\title{
Dealloyed Pt-based Core-Shell Oxygen Reduction Electrocatalysts
}

\author{
Peter Strasser $^{\mathrm{a}, \mathrm{b} *}$ and Stefanie Kühl ${ }^{\mathrm{a}}$ \\ ${ }^{a}$ Department of Chemistry, Chemical Engineering Division, Technical \\ University Berlin, Berlin 10623, Germany \\ ${ }^{b}$ Ertl Center for Electrochemistry and Catalysis, Gwangju Institute of \\ Science and Technology, Gwangju 500-712, South Korea \\ *pstrasser@tu-berlin.de
}

\begin{abstract}
Dealloyed Pt core-shell nanoparticles constitute the most active and stable bimetallic oxygen reduction catalysts for low-temperature fuel cells. Here, we review recent advances on their preparation, structural characterization, and electrocatalytic performance. Starting with bimetallic metal overlayer model systems, for which we illustrate fundamental principles of the ORR activity enhancements of dealloyed nanoparticles, we discuss progress in our understanding of structure-activity relations of dealloyed nanoparticle catalysts, both in idealized liquid-electrolyte cell formats and more realistic Membrane Electrode Assemblies (MEAs).
\end{abstract}

Keywords: oxygen reduction, core-shell nanoparticles, PtNi nanoalloy, dealloying 


\section{Introduction}

Over 2000 years ago, gold smiths of pre-Columbian Mesoamerica developed and utilized metallurgical technologies to selectively remove $\mathrm{Cu}$ atoms from tumbaga, a $\mathrm{Cu}$-rich $\mathrm{Cu}-\mathrm{Au}$ alloy material $[1,2]$, using plant and mineral extracts. As a result, they created a $\mathrm{Au}$ rich surface, making a largely $\mathrm{Cu}$-rich object look like gold (see Fig. 1). This is probably the earliest confirmed example for the use of "dealloying" to deliberately alter the surface property of a material.

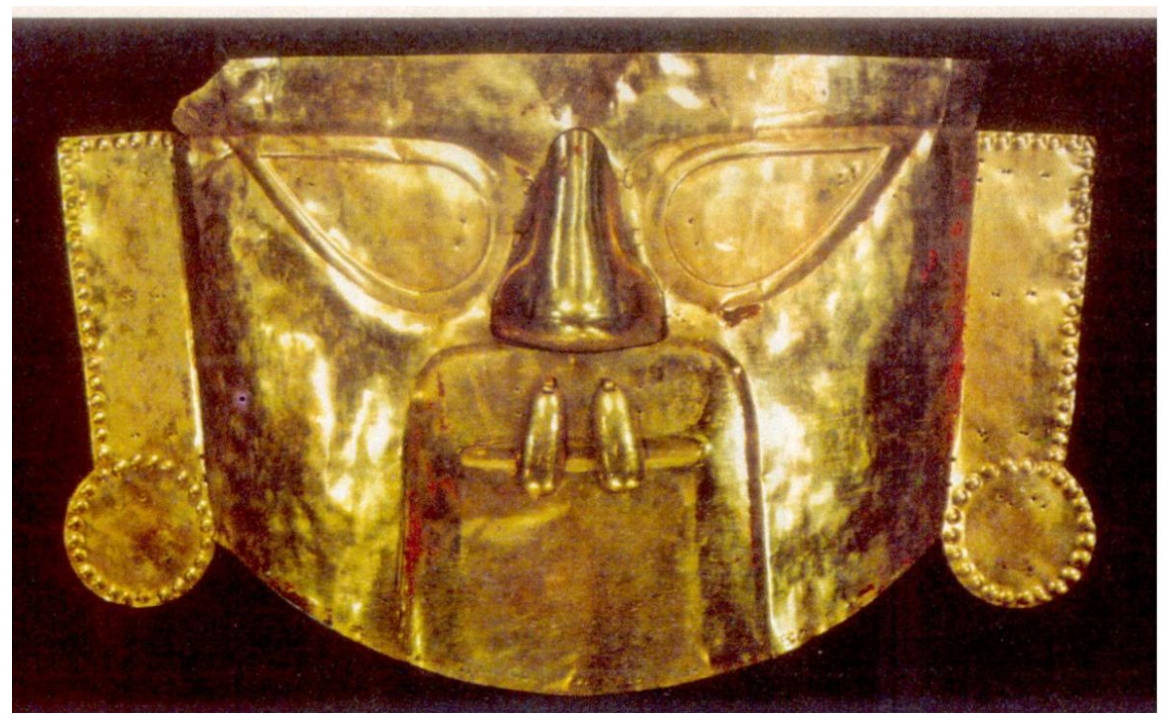

Figure 1 Dealloying changes surface properties: Precolumbian goldsmiths of the Moche culture (200 BC to 700 AD) in today's coastal regions of northern Peru mastered the metallurgical craft of "depletion gilding": $\mathrm{Cu}$ was selectively leached from tumbaga, a Cu-rich Au-Cu alloy, using natural acidic plant extracts, leaving behind an Au-enriched surface. This resulted in "golden" objects, consisting largely of $\mathrm{Cu}$ in the bulk, like this decorative mask. Source: Museo Nacional de Arqueología Antropología e Historia del Perú. Photo taken by author.

Dealloying has generally come to be known as the selective removal of a less noble component of a bimetallic alloy. The primary physical difference between dealloying and other forms of corrosion is that the size, volume, and shape of the structure undergoing attack are largely unaltered. Thus, the density of the residual dealloyed metal is less. Long before the microscopic processes of this galvanic corrosion were understood, dealloying was known to be a technological challenge to materials durability and strength. Brass tubes, for instance, suffered dezincification. But dealloying was also exploited to generate metals with extremely high surface areas that could be used in chemical process catalysis. In 1926, the American engineer Murray Raney developed high surface-area Ni powders for use as hydrogenation catalysts for vegetable oils $[3,4]$. Later on, generations of corrosion chemists and material scientists gradually studied the origin and the physical processes underlying the dealloying process using ever sophisticated techniques [5-17].

The notion of dealloying of $\mathrm{PtCr}$ and $\mathrm{PtCo}$ bulk alloys to fabricate roughened electrocatalysts emerged in the late $80 \mathrm{~s}$ and 90 s of last century in few scattered reports $[18,19]$. Starting in the 2000 s, dealloyed nanoporous metals, in particular Au, be- 
came a popular research subject as high surface-area catalyst for various heterogeneous gas phase catalytic reactions [20-25].

In 2007, the dealloying of bi- and trimetallic Pt alloy nanoparticles was reported for the first time as a promising synthetic route towards active and low-Pt nanoscale electrocatalysts [26-29]. Since then, the relation between the atomic structure and associated electrocatalytic activity of dealloyed Pt nanoparticles has been studied in much detail [30-44], in particular with respect to the electrocatalytic reduction of molecular oxygen. Figure 2 illustrates the important role of oxygen electrochemistry in the electrochemical energy storage and conversion cycle. The evolution of molecular oxygen (the oxygen evolution reaction, OER) from water is the anodic process in electrolytic devices that provides protons and electrode for the reductive production of fuels at the cathode of electrolyzers. Conversely, the electrochemical reduction of oxygen (Oxygen reduction reaction, ORR), protons and electrons to water is the chemical reaction process at cathodes of galvanic devices, such as fuel cells. Of all fuel cell types, the Polymer electrolyte membrane fuel cells (PEMFCs) have attracted substantial commercial interests over past decades [45-50], but their commercial deployment has been slow. One of the main obstacles has been the high cost of the platinum catalyst that is used in fuel cells to catalyze the ORR (see Figure 2). This is why the development of low or non-Pt ORR catalysts has been a scientific and technical priority[51, 52], as also highlighted by Rossmeisl et al. in the same special issue [53]. Recent technical development targets called for new ORR electrocatalysts with a time-stable Ptnormalized mass activity with at least 4 -fold improvement compared to state-ofthe-art Pt catalyst.

Based on a fundamental understanding of the ORR kinetics significant advances have been achieved in rational ORR catalyst development in past years. It was proposed that the intermediate oxygenated species ( $\mathrm{such}$ as $-\mathrm{OH}_{\mathrm{ad}}$ ) are bonded too strongly on the Pt surface causing high coverages of oxygenated species on the Pt surface and slow kinetics. It is therefore expected that a slightly weakened binding energy between the oxygenated species and Pt surface should result in a higher ORR activity. This could be realized by tailoring the electronic structure of the Pt surface (particularly the d-band center), as predicted by density functional calculations [54-56].

From the late 1990's, Pt alloys containing a late 3d-transition metal "M" (M = $\mathrm{Fe}, \mathrm{Co}, \mathrm{Ni}$ etc.) were found to be more catalytically active than pure Pt on ORR $[45,57-61]$. The Pt alloys, mostly close to a stoichiometric ratio of $\mathrm{Pt}_{3} \mathrm{M}$, showed around 2-fold enhancement in the Pt-mass activity. These pioneer studies provide important insights on the possible activity-enhancement mechanisms: (i) ligand effects, due to proximity of transition metals with different electron negativity and thus direct electron interaction, typically operative over one to three atomic layers; (ii) geometric effects associated with shortened nearest-neighboring Pt-Pt interatomic distances in the Pt alloys. Both of the two effects could induce a change of the electronic structure of the Pt surface and, therefore, weakens adsorption of intermediate oxygenated species.

Based on these guidelines, great progress on the structural design of Pt-based bi- and trimetallic catalysts has been achieved in past ten years, as highlighted by several recent reviews [46-48] as well as by Stamenkovic et al. in the same special 
issue [62]. For instance, the 'Pt monolayer catalysts' reported by Adzic and coworkers, which consist a single Pt monolayer supported on non-Pt metal substrate like Pd [56, 63-68], exhibited significant ORR activity enhancement based on Ptmass. Meanwhile, Stamenkovic et al. reported a class of highly active "Pt-skin catalysts", which were formed by surface segregation in $\mathrm{Pt}_{3} \mathrm{M}$ alloys upon thermal annealing, resulting in a Pt monolayer on top of a M-enriched second layer [54, 69-71]. Both of this types of highly active catalysts have in common that a single Pt monolayer is supported on the second layer containing a heteroatom, which could not only result in direct electron interaction with $\mathrm{Pt}$, but also a strain effect on the Pt monolayer caused by lattice mismatch. As a result, both ligand effect and geometric effect could contribute to their enhanced ORR activities.

Dealloyed Pt nanoparticle catalysts emerged as an alternative highly active and low-Pt catalyst concept. Much has been learned about their structural behavior and the relation between structure and activity and stability. In particular, recent research advanced our understanding of activity-durability characteristics of dealloyed core-shell particles versus dealloyed nanoporous particles, which ultimately has led to the preparation of dealloyed core shell PEMFC cathode catalysts that met or exceeded the commercialization targets [72].

In this chapter, we review recent progress in our efforts to understand the material science and catalysis of dealloyed Pt core shell nanoparticle ORR catalysts. Drawing on earlier reviews on this topic [37, 38, 73, 74], we compare bulk and nanoscale dealloying, review insights from metal overlayer model systems, discuss preparation, structure, and catalytic ORR performance of dealloyed core-shell and nanoporous particles in liquid electrolytes and in membrane electrode assemblies. We hope this contribution can help spark future work in this interdisciplinary field at the crossroads of corrosion science, materials science, and energyrelated electrocatalysis.

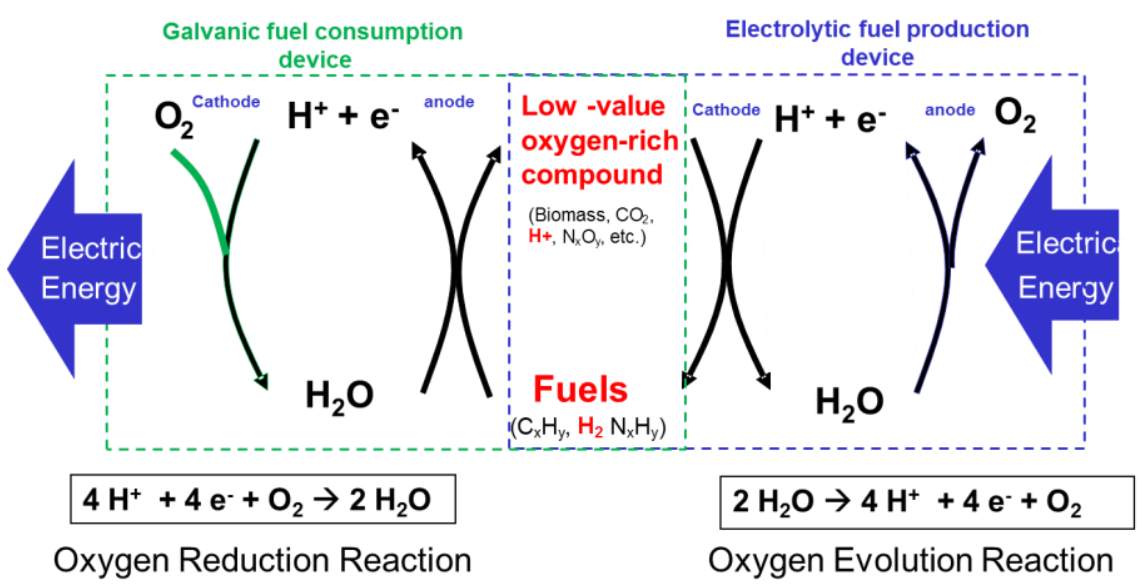

Figure 2 The artificial energy storage and conversion cycle. The Oxygen Reduction Reaction (ORR) is a sluggish process at the cathode of galvanic fuel consumption devices such as fuel cells. Its counterpart is the Oxygen Evolution Reaction (OER) which is also kinetically very challenging and limiting the rate of electrolytic fuel production devices operating in aqueous conditions, such as electrolyzers. Electrical energy input (right side) is transformed into storable fuels in electrolyzers. The fuels are subsequently oxidized in fuel cells and converted back into electrical energy (left side). 


\section{Dealloying bulk versus nanoscale bimetallics}

Dealloying, also called selective leaching, is a process where less-noble metals are selectively dissolved out of an alloy by corrosion processes. It has historically been considered to understand corrosion of technologically important alloys and the preparation of porous catalytic metals [75], such as Raney nickel. If the atomic ratio between less-noble and more-noble metal are below a structural percolation threshold, dealloying ceases at the second or so atomic layer as soon as no more less noble metal atoms are exposed to the electrolyte. Above this threshold, the dealloying process proceeds into the bulk of the alloys and generates porosity.

Inspired by the successful application of Raney nickel and recent advances in nanotechnology, there has been an increased interest in dealloyed nanoporous metals [12, 23-25, 39, 40], such as $\mathrm{Pt}, \mathrm{Pd}, \mathrm{Au}$ and $\mathrm{Cu}$. For example, nanoporous gold (Figure 3 ) was synthesized by electrochemical dealloying of a silver-gold alloy [12]. The dynamic process of dealloying was discussed using Monte Carlo simulations $[12,15,43]$. The dissolution of the less noble atoms from the topmost surface resulted in steps and kinks, where the coordinated numbers of noble atoms increased. This induced a surface diffusion of noble atoms. The competition between the dissolution rate of less noble metals and the surface diffusion of noble metals is considered as a key factor controlling the morphology of the dealloyed metal. In bulk alloys, surface diffusion rate of the noble atoms is slow across the extended surface, which causes Rayleigh surface instabilities and leads to the formation of nanoporosity $[12,43]$.

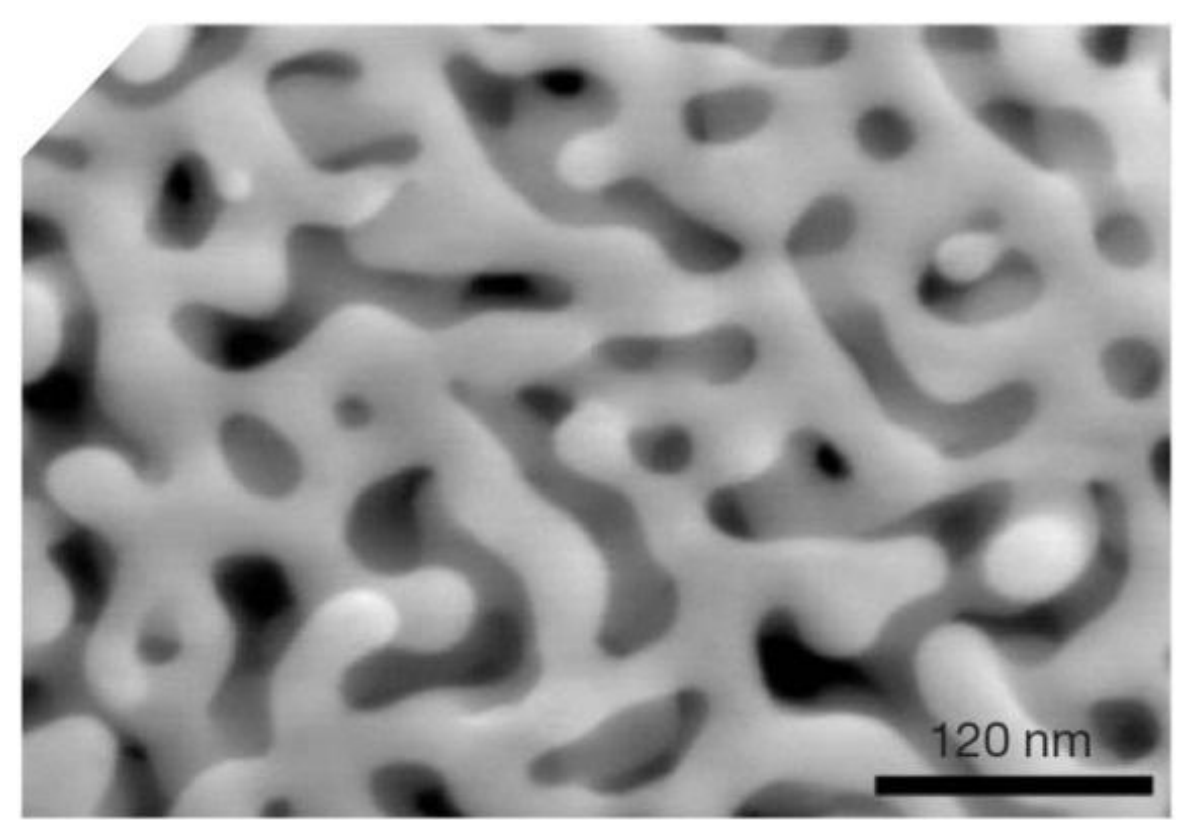

Figure 3 Nanoporosity formed by dealloying of a bulk Ag-Au alloy. Plan view of dealloyed $\mathrm{Au}_{26 \%} \mathrm{Ag}_{74 \%}($ atom\%). (Reprinted by permission from Macmillan Publishers Ltd: Nature [12], copyright (2001)). 
Dealloying of bimetallic alloy nanoparticles can be understood based on the same principles as bulk dealloying (Figure 4). The competition between surface dissolution of the less noble metal ( $\left.\mathrm{r}_{\mathrm{M}-\text {-diss }}\right)$ and Pt surface diffusion $\left(\mathrm{r}_{\mathrm{Pt} \text {-diff }}\right)$ controls the resulting nanoscale structure [76]. Small enough particles were found to generate solid, that is, non-porous core-shell nanoparticle structures. This may be due to the fact that $\mathrm{Pt}$ atoms on the surface of nanoparticles exhibit lower average coordination and, hence, diffuse faster compared to Pt atoms on bulk surfaces. This prevents Rayleigh surface instabilities and slows down the loss of the less noble metal component inside the particle core. As a result, a Pt enriched shell is formed on top of a bimetallic core [28].

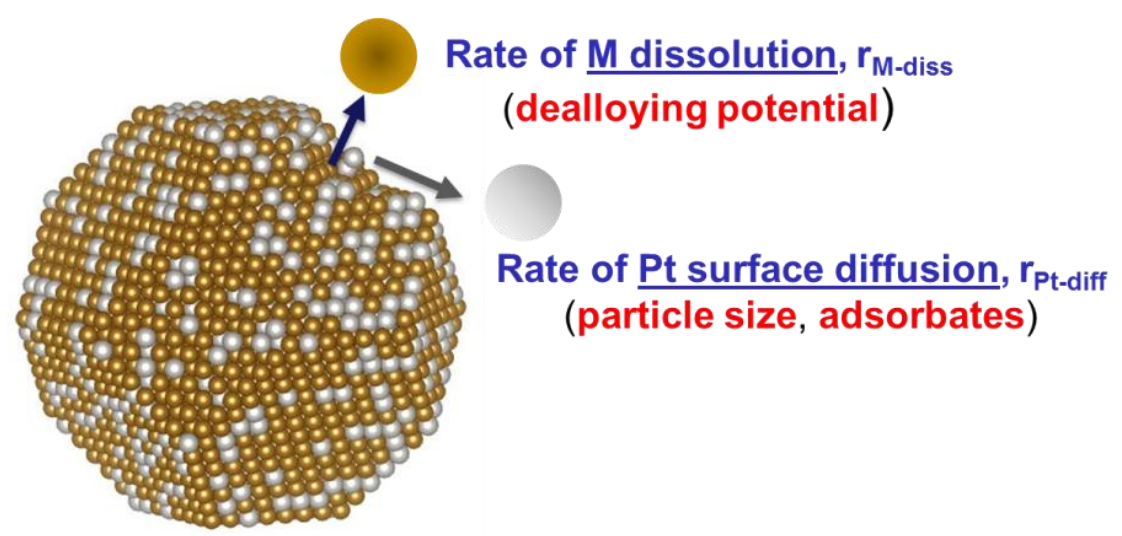

Figure 4 Nanoscale dealloying of a M-rich Pt-M bimetallic is - similar to bulk dealloying - controlled by a competition of Pt surface diffusion rate and the dissolution rate of a less noble alloy component [76]. Parameters or properties in red font can be used to change the rates of the two processes and thereby help induce or suppress deep dealloying and porosity formation.

\section{Experimental metal overlayer model studies for core-shell nanoparticles}

Sabatier's basic principle of catalysis states that a balanced interaction between reactant and catalyst should lead to optimal overall catalyst performance. Based on this, researches constructed experimental volcano-shaped relations between a catalyst's performance and heats of reaction or bond formation. In heterogeneous catalysts, the chemisorption energy of reactants on a catalyst surface emerged as a surprisingly reliable descriptor of catalytic reactivity $[77,78]$. This notion sparked theory-inspired strategies to systematically modify the surface binding energies of reactants to catalysts. For metallic surfaces, for instance, the use of geometric surface lattice strain was proposed as means to tune the binding energy of reactive intermediates, and, thus, tuning the overall catalytic rate of reaction $[79,80]$. As illustrated in Figure 5a, compressive surface strain in metals, such as Pt, should decrease the chemisorption energy of adsorbates, while tensile strain would lead to the opposite.

Experimentally, surface lattice strain was successfully introduced into a thin metal layer by depositing it onto the surface of a second metal that serves as substrate and modifies the lattice of the overlayer [32, 56, 64, 81-83]. With regards to 
electrocatalytic reaction processes, consistent experimental and theoretical correlations were reported for the hydrogen evolution reaction as well as for the oxygen reduction reaction $[64,82]$. To demonstrate the lattice deforming effect experimentally, a varying number of $\mathrm{Pt}$ overlayers were deposited on a $\mathrm{Cu}(111)$ single crystal surface and the resulting surface lattice constant was monitored (Figure 5b) $[32,73]$. Compressive lattice strain ranging from $-4.5 \%$ to about $-1 \%$ was confirmed for Pt layers starting at 1 monolayer (ML) to Pt overlayers consisting of about $15 \mathrm{ML}$. Obviously, the smaller lattice of the $\mathrm{Cu}$ substrate contracted the lattice of the Pt overlayer. According to theoretical predictions, chemisorption on these compressed Pt overlayers should be smaller than on unstrained Pt bulk surfaces [84].

a)

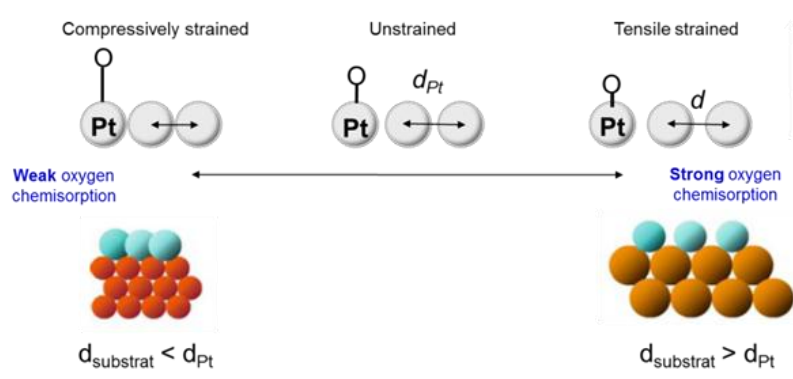

b)

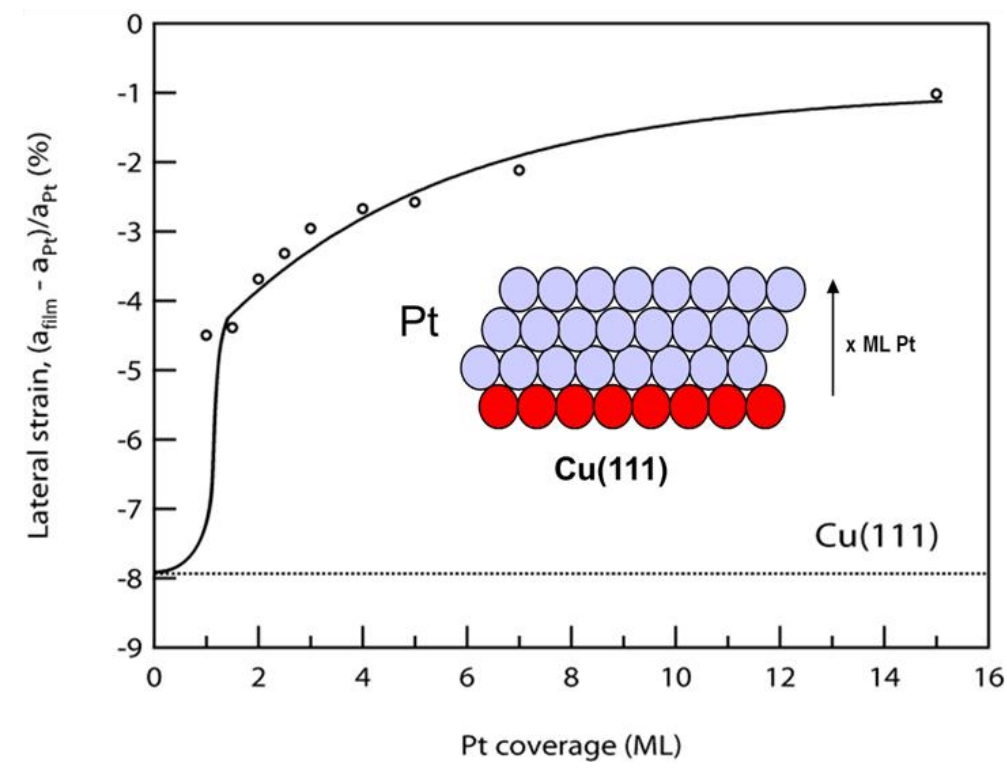

Figure 5 a) Compressive and tensile strained Pt surfaces are predicted to exhibit reduced and increased bond strengths with surface adsorbates like oxygen. Compressive strain can be induced by substrates with smaller lattice constant compared to $\mathrm{Pt}$, tensile strain by substrates with larger lattice constant. b) Strain in Pt layers deposited on $\mathrm{Cu}(111)$, defined as $\left[\left(\mathrm{a}_{\mathrm{film}}-\mathrm{a}_{\mathrm{Pt}}\right) / \mathrm{a}_{\mathrm{Pt}} \mathrm{x}\right.$ 100], deduced from LEED patterns as a function of film thickness. The curve is for guidance only. (Reprinted from "Electrocatalysis for fuel cells: a non and low Platinum approach" [73] - with permission of Springer. Remark: Graph is based on data presented in [32].) 
Density Functional Theory (DFT) computations applied to a simple mechanistic model for the ORR on well-defined closed-packed metal surfaces $[85,86]$ predicted that a chemisorbed atomic oxygen intermediate, $\mathrm{O}_{\mathrm{ad}}$, bonds somewhat too strongly on the Pt surface relative to the top of the Sabatier ORR volcano relation on similar metal surfaces. Hence, improved ORR metal electrocatalysts were predicted to be those that exhibit more positive chemisorption energies of atomic $\mathrm{O}$. Accordingly, if compressive strain weakens bond strengths, Pt overlayers on metallic $\mathrm{Cu}$ should represent a model for the surface of an improved ORR electrocatalyst. Even more, the amount by which the chemisorption of oxygen intermediates is reduced, can, in principle, be tuned by adjusting the thickness of the Pt overlayer. Indeed, it was experimentally confirmed, that Pt overlayers on $\mathrm{Cu}$ are bimetallic systems performing superior to pure Pt surface $[87,88]$.

To illustrate the fundamental origin of the lower chemisorption of adsorbates on Pt overlayers on the $\mathrm{Cu}(111)$ substrate, we probed the occupied and unoccupied portion of electronic states near the Fermi level at three Pt layer thicknesses [73], see Figure 6. The analysis revealed that a lattice strained thin Pt overlayer (compare data for 2.6 ML) exhibited a reduced amount of unoccupied projected electronic states, which can be interpreted as a down shift of the electronic $\mathrm{d}$ band center. For larger thicknesses, more unoccupied states were available consistent with a more upshifted electronic $d$ band. DFT predictions show that downshifts typically cause a weakening of adsorbate chemisorption, whereas upshifts cause the opposite [84].
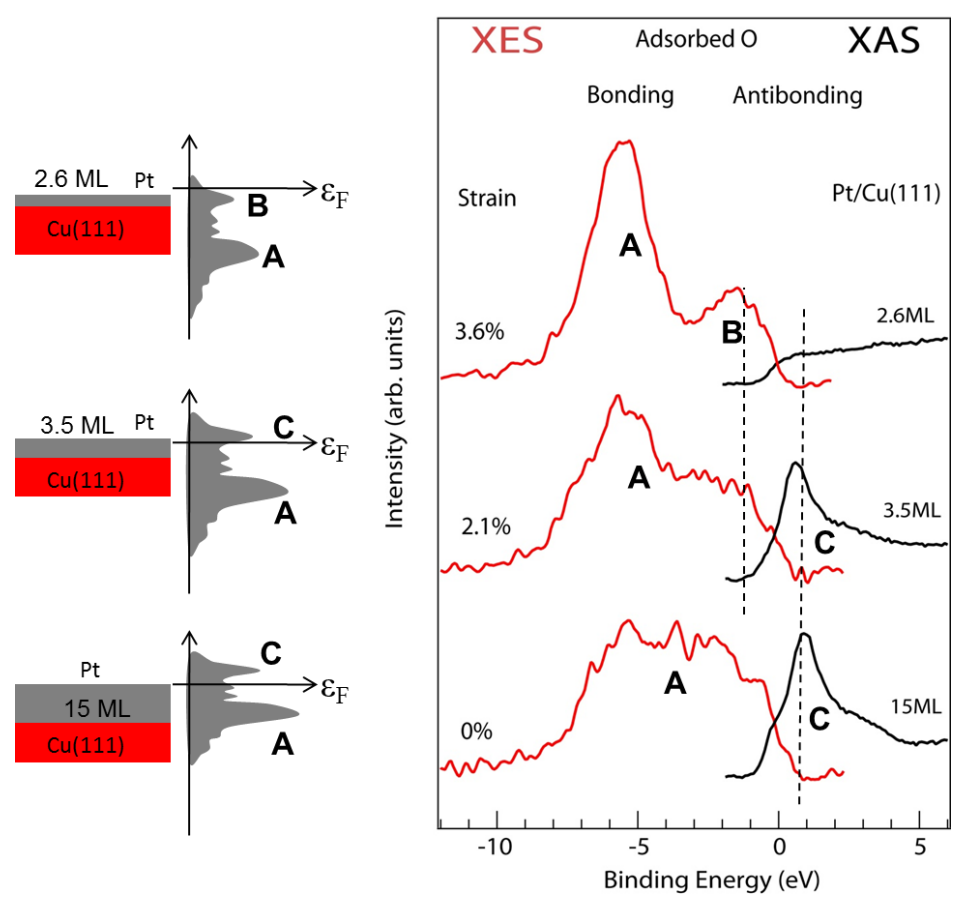

Figure 6 Pt overlayers of three varying thicknesses on a $\mathrm{Cu}(111)$ : left: schematical illustration; in the middle, their predicted qualitative $\mathrm{d}$ band structure is illustrated, in particular the position of their d bands relative to their Fermi Energy level; on the right side oxygen K-edge X-ray absorption and emission results are shown (of 0.2 ML of oxygen chemisorbed), demonstrating a downshift of the $\mathrm{O}$ projected bands, seen by the vanishing XAS feature and the additional XES 
feature B. (Reprinted from "Electrocatalysis for fuel cells: a non and low Platinum approach" [73] - with permission of Springer. Remark: Graph is based on data presented in [32].)

The results from metal overlayer studies form the basis for the notion of nanoscale Pt core-shell bimetallic electrocatalysts, where the metallic $(\mathrm{Cu})$ core controls the lattice geometry and the sign of the lattice strain in the Pt overlayer shell. Accordingly, both the thickness of the shell and the lattice constant of the core can be used to tune the magnitude of its lattice strain.

\section{Dealloyed Pt-bimetallic core-shell nanoparticle catalysts}

\subsection{Synthetic pathways toward bimetallic Pt core-shell nanocatalysts}

Different reliable and elegant synthetic pathways towards bimetallic core-shell nanoparticles were developed by chemists and material scientists. In Figure 7 an overview is illustrating the basic approaches to prepare bimetallic Pt-X core-shell particles [74], which are established and reported to date. In general, three different concepts were used: (I) "dealloying" - selective removal of one component from an uniform alloy precursor (route A, B), (II) "segregation" - treatment of an uniform alloy precursor to force one component to segregate toward the surface (or into the bulk) - thermodynamic effect (route C, D), or (III) "deposition" - deposition of one metal onto a second one (routes E, F). Therein, the electrochemical dealloying (corrosion) of Pt-poor precursor alloy nanoparticles (route A) involves selectively leaching of the less noble metal X (blue balls in Fig. 7), resulting in a nanostructured bimetallic particle with a Pt (grey balls in Fig. 7) rich shell and a Pt-poor core. Route B is related to route A, as the dealloying is caused by fast acid corrosion in liquid inorganic acids, rather than the application of an electrochemical potential protocol - the nonprecious metal atoms immediately dissolve from near-surface regions upon contact with acid. Furthermore, routes $\mathrm{C}$ and $\mathrm{D}$ harness segregation phenomena, which is often encountered in bimetallic alloys. Here, route $\mathrm{C}$ involves the adsorption of a strong binding molecule, such as $\mathrm{CO}$, on the surface of the nanoalloy. Due to its preferential interaction with $\mathrm{Pt}$, a Pt surface enrichment associated with the formation of a Pt rich shell occurs upon chemisorption. Depending on the segregation kinetics, prolonged or repeated exposure of the adsorbate may be necessary. Route D, on the other hand, takes advantage of thermal segregation phenomena of bimetallic nanoparticles. Thermal treatment of Pt alloys causes Pt atoms to diffuse to the surface, if their surface energy is lower than that of metal X. It should be noted that the segregation behavior can be critically dependent on the detailed annealing conditions; thus, in presence of reactive or strongly adsorbing gas molecules the thermal treatment may also lead to surface segregation of X. Route E in Figure 7 represents the classical seeded growth strategy, a very common synthetic pathway to build up nanostructures consisting of multiple layers of different metals. After synthesis of nanoparticles of metal X, these particles are treated with Pt precursors under reducing conditions, which causes Pt atoms to deposit on the surface of the seeds. Thereby, temperature, precursor concentrations, and a variety of other synthetic conditions determine the amount and rate of the Pt deposition and, thus, the thickness and morphology of the Pt shell. Finally, synthetic route F is based upon the spontaneous, galvanic displacement of less-noble surface metal atoms M by Pt atoms [89]. The redox dis- 
placement proceeds electrolessly, that is, at open circuit conditions without potential control, via the scheme

$$
\mathrm{M}+\mathrm{Pt}^{2+} \rightarrow \mathrm{M}^{2+}+\mathrm{Pt}
$$

Two implementations of this displacement reaction are feasible. First, electrochemical underpotential deposition of a third metal $\mathrm{M}$ onto the seeds of $\mathrm{X}$ can be used to create defined layers of $\mathrm{M}$ on X. Subsequent replacement of M with Pt via equation (1) yields the Pt-X bimetallic core-shell nanoparticles. Alternatively, $\mathrm{Pt}$ precursors may react directly with nanoparticle seeds of $X$ according to (1). The latter routes, however, typically does not result in Pt shells with well-defined thickness [74].

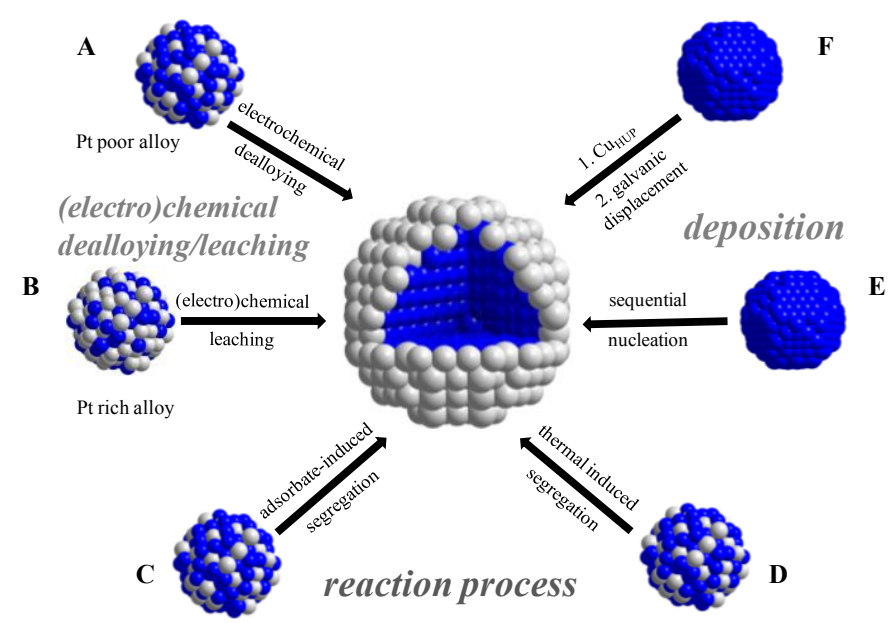

Figure 7 Illustration of basic synthesis approaches for the preparation of Pt-X core-shell nanoparticles (grey balls: Pt, blue balls: a less noble metal X). Electrochemical (acid) dealloying/leaching results in (A) dealloyed Pt bimetallic core-shell nanoparticles and (B) Pt-skeleton core-shell nanoparticles, respectively. Reaction process routes generate segregated Pt skin coreshell nanoparticles induced either by (C) strong binding to adsorbates or (D) thermal annealing. The preparation of (E) heterogeneous colloidal core-shell nanoparticles and (F) Pt monolayer core-shell nanoparticles is via heterogeneous nucleation and UPD followed by galvanic displacement, respectively. (Reprinted with permission from ref. [74] - Copyright 2013 American Chemical Society.)

Current research efforts in the area of synthesis of core-shell particles are focused on an improved control of the Pt shell thickness, the size of the core-shell particles, and the stabilization of the less noble core under electrochemical conditions. These parameters are the key to the ORR activity and long-term stability of the nanoparticles.

\subsection{Dealloyed $\mathrm{PtCu}_{3}$ core-shell ORR nanoparticle electrocatalysts}

For the investigation of core-shell particles as catalysts in ORR carbonsupported dealloyed Pt-Cu nanoparticle catalysts were prepared, starting with the synthesis of $\mathrm{PtCu}_{3}$ alloy precursor, followed by electrochemical dealloying (route 
A in Figure 7) [26, 31, 32, 90, 91]. Figure 8a shows the initial and the final cyclic voltammetric scan during the dealloying of the precursor [90]. The initial strong voltammetric waves indicate the dissolution of $\mathrm{Cu}$ surface atoms. The final profile resembles that of pure Pt suggesting a Pt rich surface has formed. Figure $8 \mathrm{~b}$ displays an elemental map (EDX) of the dealloyed catalyst particles taken during a scanning transmission electron microscopic (STEM) study. Most particles are characterized by a $\mathrm{Pt}$ rich shell surrounding a $\mathrm{Pt}-\mathrm{Cu}$ alloy core. Also individual pure $\mathrm{Pt}$ atoms or pure Pt atomic clusters on the carbon support have been observed.

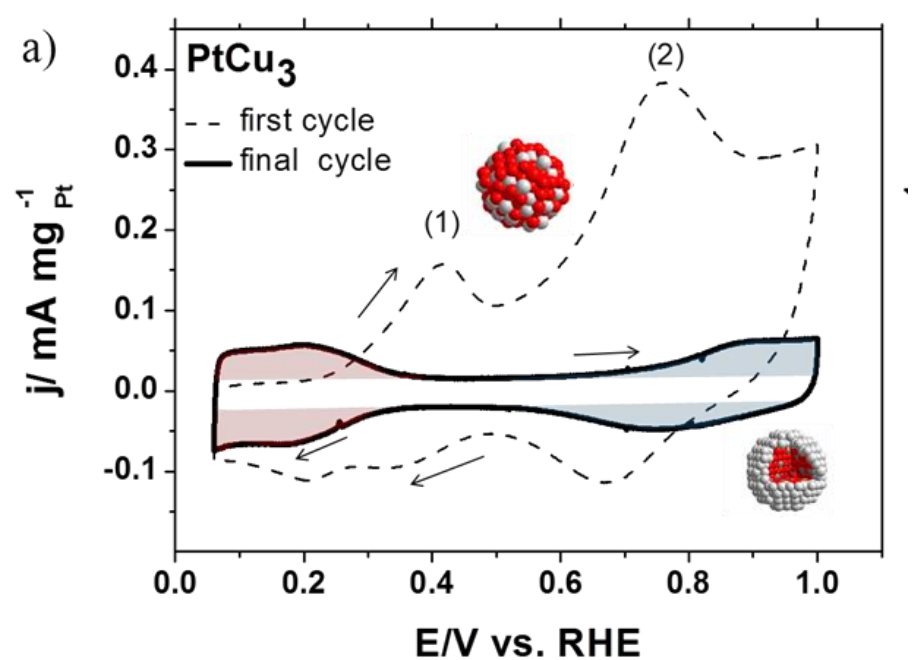

b)

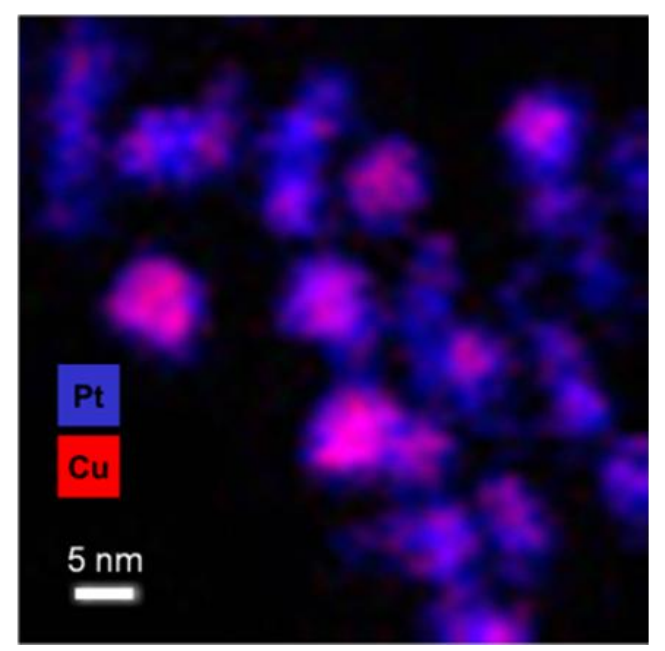

Figure 8 (a) Initial and final voltammetric profiles during electrochemical dealloying of a $\mathrm{PtCu}_{3}$ precursor alloy, insets show structural cartoons of a precursor alloy particle and a dealloyed coreshell particle, grey and red balls denote $\mathrm{Pt}$ and $\mathrm{Cu}$ atoms. (Reproduced with permission from ref. [90] - Copyright 2012 American Chemical Society.)

(b) STEM/EDX elemental mapping of $\mathrm{Cu}$ and $\mathrm{Pt}$ in dealloyed $\mathrm{Pt}-\mathrm{Cu}$ nanoparticles, $\mathrm{Pt}$ blue, $\mathrm{Cu}$ red. (Reprinted with permission from ref. [74] - Copyright 2013 American Chemical Society.)

The carbon supported dealloyed $\mathrm{PtCu}_{3}$ catalysts showed excellent catalytic ORR activities in rotating disk electrode measurements displaying unprecedented 
3-5 fold improvements in the Pt-mass-activity compared to pure Pt at $0.9 \mathrm{~V}$ vs. RHE. Evidently, electrochemical dealloying of Pt-poor bimetallic alloys significantly alters the catalytic behavior of the resulting Pt core-shell particles.

To establish a correlation between lattice strain in the Pt shell of the dealloyed particle and their ORR activity, the compressive strain in the Pt shell was estimated by anomalous X-ray diffraction (AXRD) analysis using a simple two-phase model [32]. In a series of experiments, the magnitude of compressive strain increased with initial $\mathrm{Cu}$ content. This can be well understood based on the coreshell model. The lattice mismatch between the Pt shell and the Pt-Cu alloy core causes a reduced $\mathrm{Pt}-\mathrm{Pt}$ distance in the shell; the richer in $\mathrm{Cu}$ the particle core is, the smaller its lattice parameter, and, hence, the higher the compressive strain ideally induced in the shell. Figure 9 shows the correlation between ORR activity and compressive lattice strain evidencing that geometric lattice strain can be used to continuously tune the catalytic activity of core-shell nanoparticle catalysts [92]. The plot also contain the theoretically predicted volcano relation between ORR reactivity and compressive lattice strain in an well-ordered $\mathrm{Pt}(111)$ surface. Strain relaxation effects in the Pt shell may complicate or prevent the experimental observation of the right branch of the volcano curve.

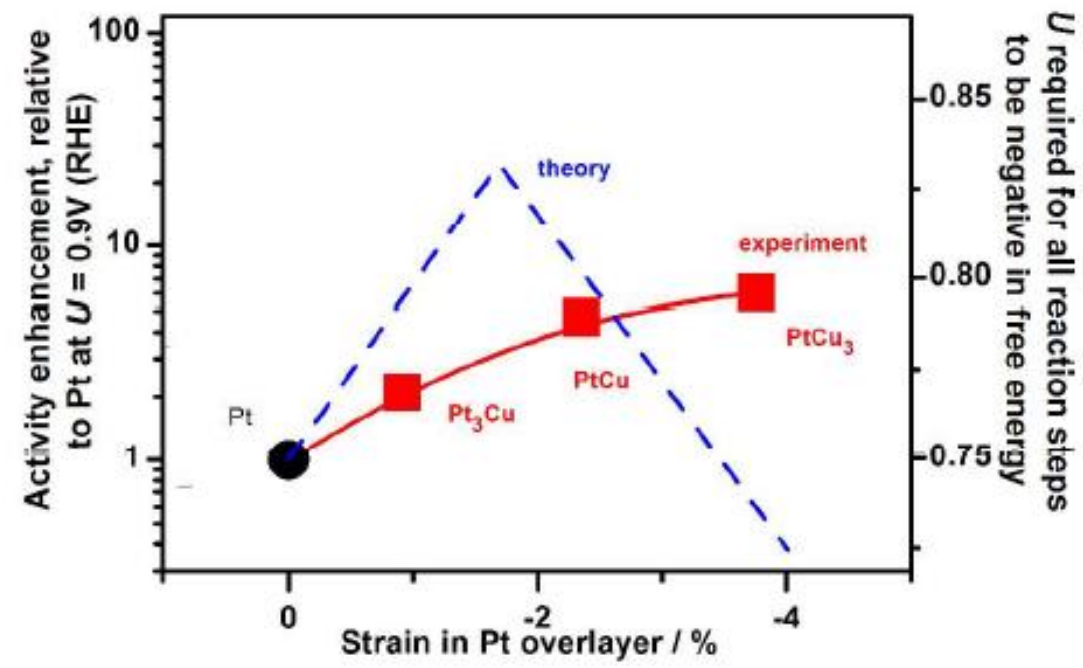

Figure 9 Experimental (red squares) and DFT predicted (blue dashed line) relationships between ORR activity enhancement (left y axis) and lattice strain at $\mathrm{T}=298 \mathrm{~K}$. (The data were taken from the particles that were preannealed at $800^{\circ} \mathrm{C}$.) The experimental ORR activities of dealloyed Pt$\mathrm{Cu}$ nanoparticles are plotted as a function of surface lattice strain in the particle shell (red line to guide the eye). The DFT-predicted volcano-shaped reactivity trend represents the ORR activity of a $\operatorname{Pt}(111)$ single-crystal slab under isotropic strain. Right y axis denotes the electrode potential required for all elementary reaction steps of the ORR model to be downhill in free energy. Moderate compressive lattice strain is predicted to enhance the rate of ORR catalysis. (Reproduced from ref. [92] with permission of The Royal Society of Chemistry.) 
4.3 Dealloyed Pt bimetallic nanocatalysts with other transition metals

The dealloyed core-shell nanoparticle concept first exemplified using the Pt-Cu system was later generalized to other PtX alloy systems, with X being a non-noble transition metal. Figure 10 correlates the intrinsic ORR activities with the bulk lattice parameters of various $\mathrm{PtX}_{3}$ precursors [26, 31, 93-96], prepared at two different annealing temperatures. Clearly, the red $\left(950^{\circ} \mathrm{C}\right)$ and black $\left(800^{\circ} \mathrm{C}\right)$ catalysts evidenced a strong correlation between intrinsic catalytic ORR activity and bulk lattice parameter of the precursor nanoparticles. The larger the atomic radius of metal X, the larger was the lattice parameter in their $\mathrm{PtX}_{3}$ alloy precursor. This is consistent with Vegard's rule and indicates that all of the analyzed alloy phases qualitatively follow that rule. Also, the $950^{\circ} \mathrm{C}$ alloy precursors exhibited typically somewhat smaller lattice parameters, closer to their ideal Vegard's value. This is plausible as a higher annealing temperature is conducive for the formation of a single-phase alloy with a higher degree of alloy homogeneity. These trends are consistent with the notion that nanoparticle alloys exhibiting smaller lattice parameters will result in dealloyed Pt core-shell catalysts with an increasingly compressively strained Pt shell; which, in turn, lowers the chemisorption energy of oxygen intermediates and, thus, results in a higher overall reaction rate for ORR. Certainly, other microscopic factors, such alloy homogeneity or nanoparticle size, will co-influence the catalytic activity, as well, as the correlations are by far not perfect. However, these qualitative trends in Figure 10 support the concept that for this family of catalysts geometric factors of the precursor alloy play an important role, as they have a significant influence on the final ORR activity after dealloying.

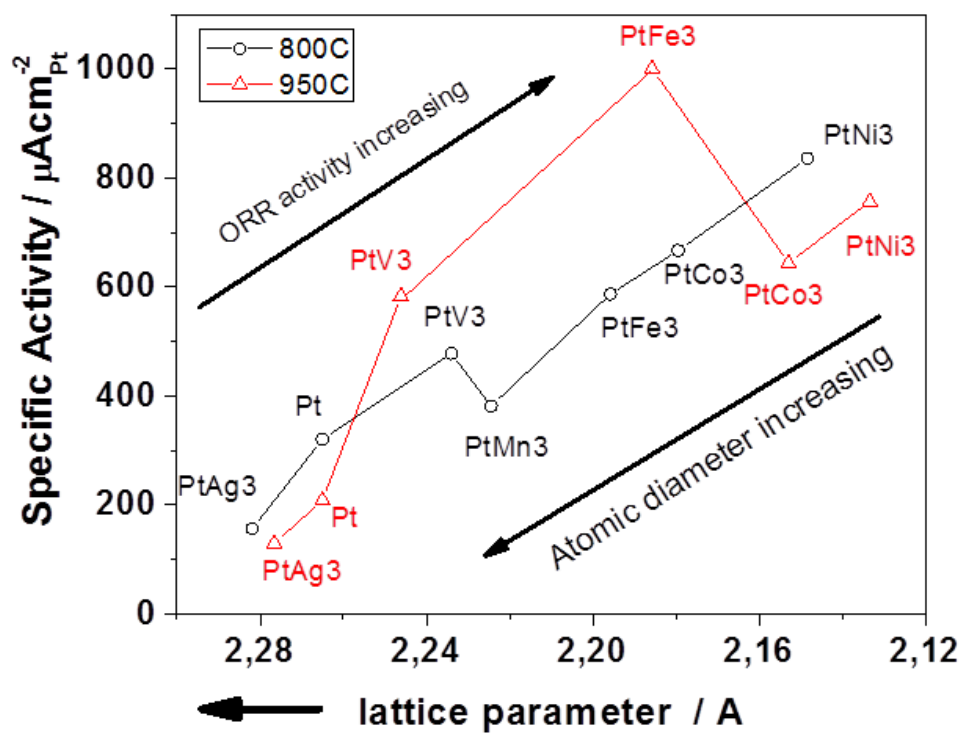

Figure 10. Intrinsic (specific) catalytic ORR activity of dealloyed $\mathrm{Pt}-\mathrm{X}(\mathrm{X}=\mathrm{Ag}, \mathrm{V}, \mathrm{Mn}, \mathrm{Fe}, \mathrm{Co}$, Ni) core-shell alloy nanoparticles as a function of the experimental lattice parameter of their initial PtX3 nanoparticle precursor. Red and black data points denote precursors prepared using annealing at $950^{\circ} \mathrm{C}$ and $800^{\circ} \mathrm{C}$, respectively. Activity was evaluated with respect to the Pt-based electrochemical surface area (ECSA) determined using hydrogen underpotential deposition. Synthesis details are given in ref. [28]. The $950^{\circ} \mathrm{C}$ data point of Pt-Mn is missing. Black arrows highlight the strong correlation of lattice parameter/atomic radius and final ORR activity. 


\section{Dealloyed Pt-Ni Core-Shell Catalysts}

Reports on favorable ORR activity trends of bimetallic Pt nanoparticles (NPs) combined with own measurements, such as shown in Figure 10, raised interest in the dealloyed Pt-Ni system. A series of $\mathrm{Pt}_{\mathrm{x}} \mathrm{Ni}_{1-\mathrm{x}}$ alloy NP precursors, $\mathrm{PtNi}, \mathrm{PtNi}_{3}$ and $\mathrm{PtNi}_{5}$, see Figure $11 \mathrm{a}-\mathrm{c}$, was prepared using an ambient-pressure hot-injection synthesis route $[34,97]$. The particle size generally increases with increasing initial Ni content, indicating the coupling between the size and the composition [98]. The NPs were subsequently dispersed onto high surface-area carbon supports (Figure 1d).

Dealloyed core-shell $\mathrm{Pt}_{\mathrm{x}} \mathrm{Ni}_{1-\mathrm{x}} \mathrm{NPs}$ (hereafter denoted as " $\mathrm{D}-\mathrm{Pt}_{\mathrm{x}} \mathrm{Ni}_{1-\mathrm{x}}$ ") were obtained by potential cycling [34] and were then subjected to ORR measurements (Figure $11 \mathrm{e}-\mathrm{f}$ ). All D-Pt $\mathrm{Ni}_{1-\mathrm{x}}$ catalysts exhibited significantly enhanced ORR activities compared to a commercial $3 \mathrm{~nm}$ Pt catalyst. The D-PtNi ${ }_{3}$ catalyst showed the highest mass activity and specific activity, roughly $5 \mathrm{x}$ and $10 \mathrm{x}$ enhancement over $\mathrm{Pt}$, respectively. In line with its highest activity, the $\mathrm{D}-\mathrm{PtNi}_{3}$ also exhibited the highest residual Ni content (Figure 11e). This result underlines the importance of retaining a high content of the transition metal in the dealloyed NPs to achieve optimal ORR activity and is fully consistent with previous reports by Wang et al. [99]. The findings are also consistent with earlier findings for dealloyed $\mathrm{Pt}-\mathrm{Cu}$ nanoparticles discussed in section 4.
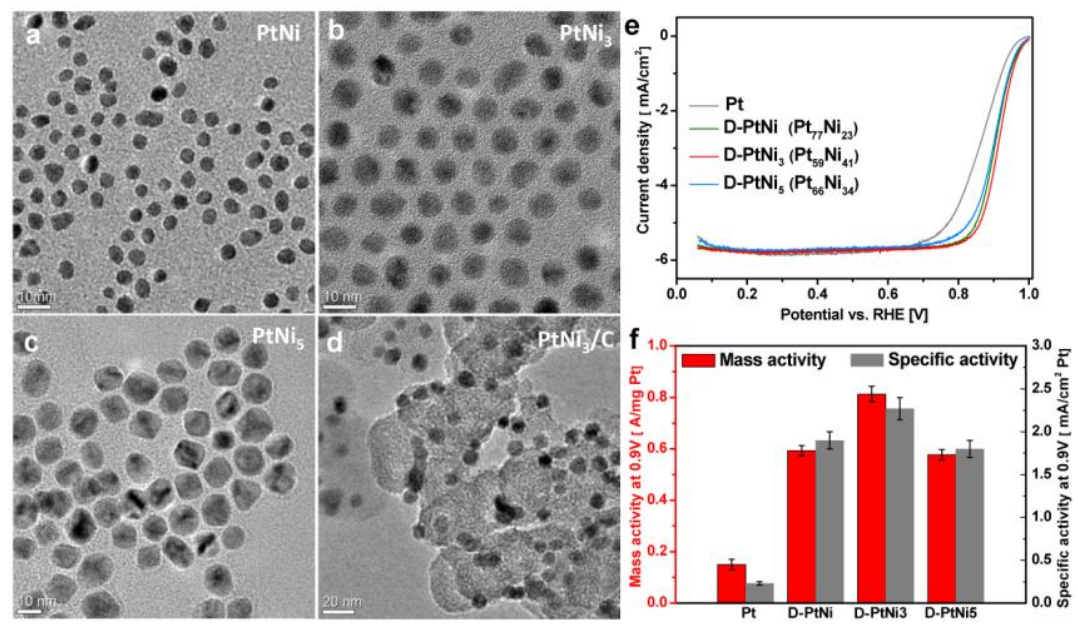

Figure 11 TEM images of (a-c) monodispersed PtNi, $\mathrm{PtNi}_{3}$ and $\mathrm{PtNi}_{5} \mathrm{NPs}$ and (d) $\mathrm{PtNi}_{3} \mathrm{NPs}$ dispersed on Vulcan XC-72 carbon support. (e) ORR voltammograms of dealloyed $\mathrm{Pt}_{\mathrm{x}} \mathrm{Ni}_{1-\mathrm{x}}$ catalysts on $\mathrm{RDE}$ at $1^{\prime} 600 \mathrm{rpm}$ in $\mathrm{O}_{2}$-saturated $0.1 \mathrm{M} \mathrm{HClO}_{4}$ at $5 \mathrm{mV} / \mathrm{s}$. (f) Comparison of mass and specific activity at $0.9 \mathrm{~V}$. (Reprinted from ref. [38] (Top. Catal.), with permission of Springer. Remark: Graphs are based on data presented in [34].)

Despite the correlation between overall residual bulk Ni content and ORR activity, catalytic surface activities of the dealloyed core-shell NPs are primarily dependent on the surface composition than the overall bulk composition. As a result of this, despite identical bulk compositions, Pt alloys with varying near-surface compositions manifest distinctly different ORR activities [69, 71]. Knowledge and insight into the near-surface composition of core-shell NPs, more specifically, the 
Pt shell thickness and the distribution of the non-noble transition metals in the subsurface layers is therefore crucial for a fundamental atomic scale understanding of their electrocatalytic properties. Recently, Wang et al. [99] highlighted the critical role of Pt shell thickness in controlling the ORR activities, where higher initial $\mathrm{Ni}$ compositions in $\mathrm{Pt}_{\mathrm{x}} \mathrm{Ni}_{1-\mathrm{x}}$ (from $\mathrm{Pt}_{3} \mathrm{Ni}$ to $\mathrm{PtNi}_{3}$ ) catalysts was reported to result in a higher extent of $\mathrm{Ni}$ dissolution and thereby thicker pure Pt shells and, as a result of this, ultimately lower ORR activity. This can be explained in terms of strain relaxation across the Pt shell [100] leading to reduced compressive strain in the outermost Pt surface layer and, thus, lower ORR activities. Using aberrationcorrected STEM-EELS with high spatial resolution and high efficiency, recent studies $[34,38]$ showed that increases in the initial Ni composition $\left(\mathrm{PtNi}_{5}\right)$ lead to a decrease in the Pt shell thickness (Figure 12) demonstrating a more complex relation between initial composition and Pt shell thickness than previously thought.

The D-PtNi ${ }_{3}$ catalyst exhibited the highest ORR activity even though it showed the largest Pt shell thickness, see Figure 11f. This finding evidences that the Pt shell thickness is an incomplete descriptor for experimental activity trends in D$\mathrm{Pt}_{\mathrm{x}} \mathrm{Ni}_{1-\mathrm{x}}$ catalysts. Instead, the distribution of transition metals at and below the surface (down to $\sim 10$ atomic layers from surface) appeared to play a much more important role for the ORR activities [34].

Also in Figure 12 an unusual non monotonic modulation of the Ni distribution across the alloy particle core is evident in Ni-rich Pt alloys (D-PtNi $i_{3}$ and $\mathrm{D}-\mathrm{PtNi}_{5}$ ), showing the formation of near-surface Ni-enriched inner shells [38]; in contrast, D-PtNi NPs exhibited a conventional core-shell structure. The location and the composition of the Ni-enriched inner shells were sensitively dependent on the initial alloy compositions. At higher initial Ni compositions (D-PtNi ${ }_{5}$ ), the Nienriched inner shell moved closer to the surface, while the Ni composition at the inner shell decreases. The $\mathrm{D}-\mathrm{PtNi}_{3}$ catalyst exhibited the highest content of $\mathrm{Ni}$ at the subsurface layers, which, in turn, raised the compressive lattice strain on the $\mathrm{Pt}$ surface and, presumably, counterbalanced any strain relaxation over its larger $\mathrm{Pt}$ shell thickness. This resulted into the highest ORR activity.

The unusual core-shell fine structures discovered here provided a more complete picture, how the initial alloy particle compositions influence the ORR activities. Our data strongly suggest that the Ni distribution at the near surface (up to 10 atomic layers) plays a much more important role in the control of lattice strain [38] and, hence, catalytic reactivity of the outermost Pt layer than previously assumed. The local Ni enrichment is in line with other studies that reported phasesegregated subsurface Ni domains in dealloyed $\mathrm{PtNi}_{3}$ NPs [101]. The mechanistic origin of the self-organization of Ni-rich inner shells has remained elusive. Possible mechanisms were put forward invoking either an inverse Kirkendall effect during the dealloying process or an outward segregation due to the strong oxophilicity of $\mathrm{Ni}[34,35]$. 

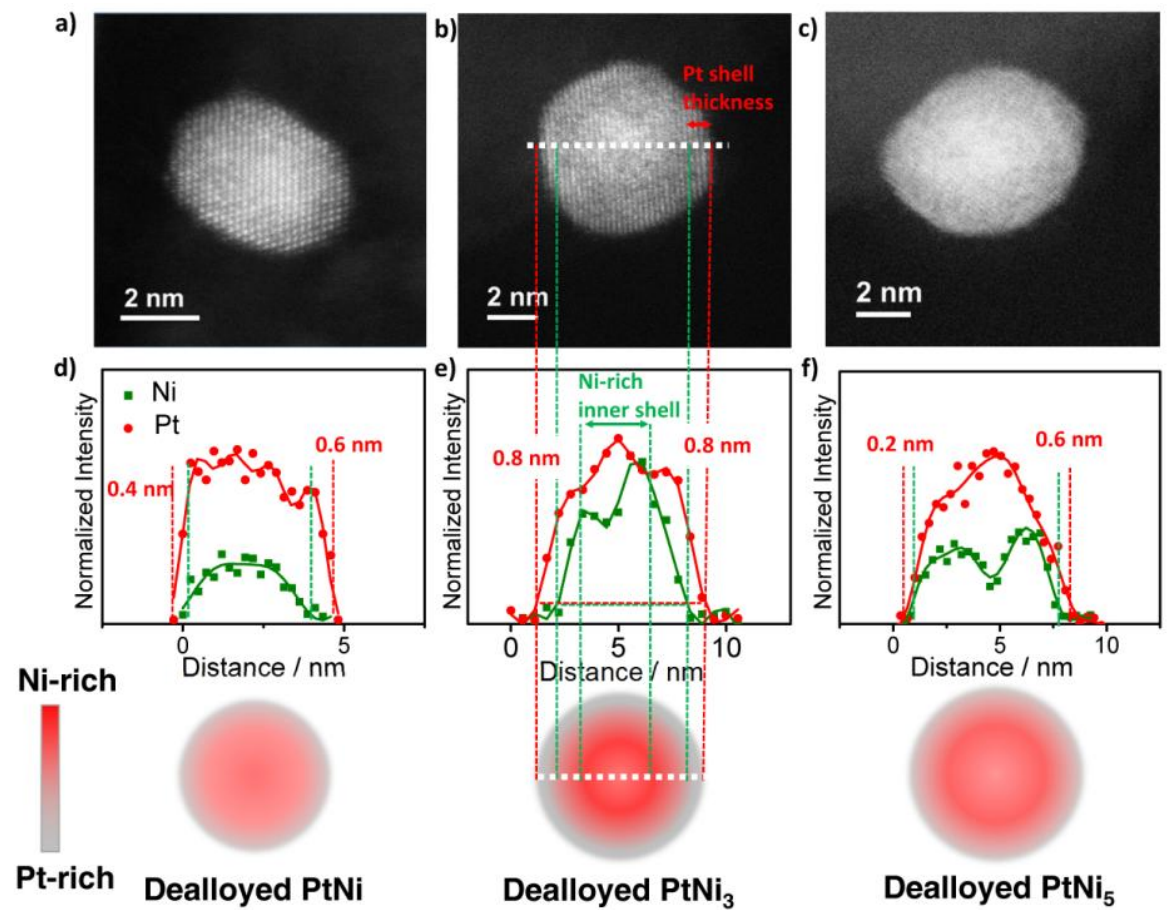

Pt-rich Dealloyed PtNi

Dealloyed $\mathrm{PtNi}_{3}$

Dealloyed $\mathrm{PtNi}_{5}$

Figure 12 High resolution HAADF-STEM images of dealloyed PtNi (a), $\mathrm{PtNi}_{3}$ (b) and $\mathrm{PtNi}_{5}$ NPs (c), and EELS line compositional profiles (d-f) across the NPs, respectively. Bottom line: Structural model of distinctly different compositional core-shell fine structures of dealloyed $\mathrm{Pt}_{\mathrm{x}} \mathrm{Ni}_{1-\mathrm{x}}$ catalysts. (Reprinted from ref. [38] (Top. Catal.), with permission of Springer. Remark: Graphs are based on data presented in [34].)

In analogy to dealloyed Pt-Cu ORR nanoparticle catalysts, solid spherical coreshell Pt-Ni NP often coexist with nanoscale Pt-Ni particles exhibiting nanoporosity in form of highly irregular pores, pits and voids in their interior (also called "spongy" or "swiss cheese" type particles) [41, 44, 90, 102-104]. As outlined in section 2, nanopores in NPs can form spontaneously during the dealloying of Pt alloy NPs if the particle size exceeds a critical value $[44,90]$. Nanoporosity in bimetallic Pt-Ni alloys can be perceived as an effective and beneficial strategy to enhance the catalytic activity owing to an increased surface area [39, 44, 102]. However, the effect of nanoporosity on the particle composition, on surface lattice strain, and, related to these, on ORR activity and stability needs to be considered as well.

To reach a conclusion, whether solid core-shell or nanoporous NP architectures are desirable for the design of an active and stable Pt alloy ORR NP electrocatalyst, two identical $\mathrm{PtNi}_{3}$ precursor NP ensembles were transformed into nanoporous (see Figure 13a) and solid core-shell NPs (Figure 13d) [76], respectively. The nanoporosity formation showed a strong size-dependence $(>13 \mathrm{~nm})[44,90]$ and was invariably tied to a drastic loss of bulk Ni (Figure 13c). This can be understood considering the porosity formation mechanism, involving fast $\mathrm{Ni}$ dissolution and a slower diffusion of $\mathrm{Pt}$ atoms so that Rayleigh surface instabilities can occur and propagate $[12,43]$. A significant loss in Ni in the porous NPs, however, is linked to reduced surface lattice strain and as such to lower intrinsic electrocatalytic ORR activity [38], which can be seen by comparing the initial specific activities 
in Figure 13b and 13e. Anyway, nanoporosity can indeed enhance the overall mass activity thanks to increased surface area. It is most effective for bulk-like catalytic materials, where surface area effects dominate. However, in small dealloyed bimetallic NPs, where surface lattice strain effects outweigh intraparticle surface area effects, the loss of intrinsic catalytic activity due to nanoporosity typically compensates the beneficial effect of increased surface area. In this context, nanoporosity does not provide any benefit for the overall mass activity and turns into an undesired characteristic of active alloy NP electrocatalysts [38].
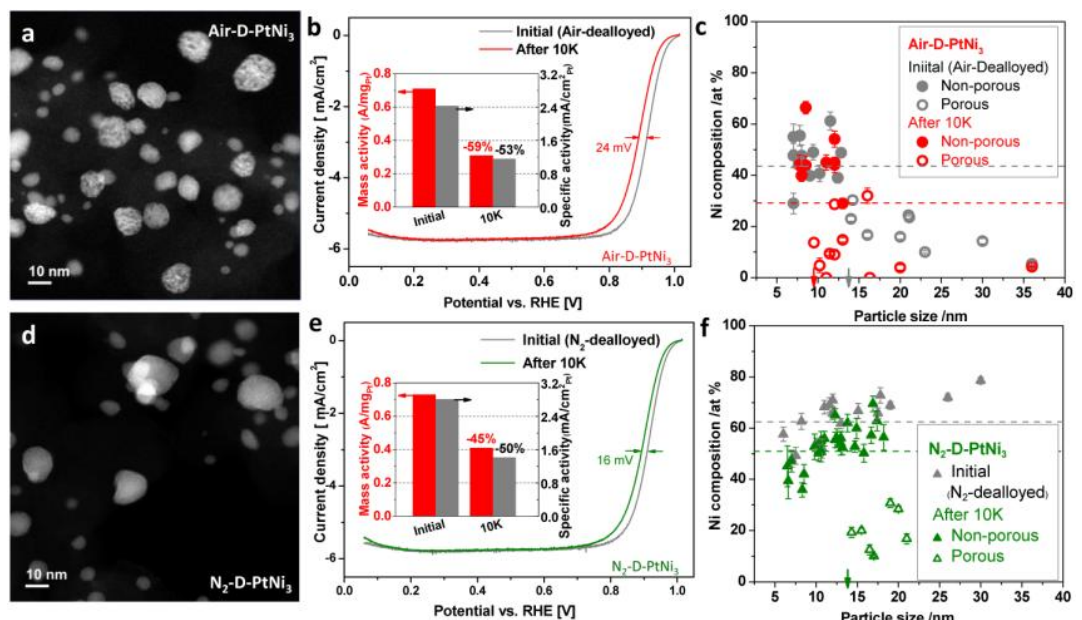

Figure 13 ORR activity and stability analysis of (a-c) Air-D-PtNi 3 catalyst and (d-f) $\mathrm{N}_{2}-\mathrm{D}-\mathrm{PtNi}_{3}$ catalyst: (a, d) HAADF-STEM images of the catalysts after dealloying but before stability test, (b, e) ORR activity and stability after 10,000 cycles between 0.6 and $1.0 \mathrm{~V}$, and (c, f) Sizecomposition-porosity information before and after stability test (dash lines represent the average Ni content). (Reprinted from ref. [38] (Top. Catal.), with permission of Springer. Remark: Graphs are based on data presented in [76].)

In subsequent studies, nanoporosity was found to be conducive to activity degradation during long-term stability testing [76]. Comparing results in Figure 13b and $13 \mathrm{e}$, it is evident that the non-porous catalyst with a solid core-shell structure was substantially more stable compared to the nanoporous catalyst $[38,76]$. Statistical size-composition-porosity analysis by TEM/EDX further uncovered that, in the nanoporous catalyst the particle size threshold where nanoporosity became possible, had shifted to smaller particle sizes (Figure 13c). In contrast, despite identical subsequent catalytic testing, the solid core-shell NPs behaved much more durable against later-stage nanoporosity formation. In fact, nanoporosity was limited to few particles larger than $15 \mathrm{~nm}$ (Figure 13f) and otherwise effectively suppressed. This caused higher residual Ni content retained in catalyst NPs after the stability test, accounting for its higher stability. Even more, an unsual "volcano-shaped" size dependence of ORR activity and stability was found for $\mathrm{PtNi}_{3}$ alloy NPs obtained in a size-controlled synthesis [105]. The NPs with sizes between 6-8 $\mathrm{nm}$ showed the highest activity as well as stability due to their highest retained Ni content.

Figure 14 presents the morphology and composition profiles of $\mathrm{D}-\mathrm{PtNi}_{3} \mathrm{NPs}$ after an ORR stability test over a broad size range [38]. Smaller NPs exhibited a close-to-ideal solid core-shell structure with a higher residual $\mathrm{Ni}$ content in the 
core and also a thinner Pt shell thickness ( 3-5 atomic layers) [38, 76]. With increasing particle size above $10 \mathrm{~nm}$, however, nanoporosity emerged and was invariably coupled to a reduced $\mathrm{Ni}$ content in the core associated with an increased $\mathrm{Pt}$ shell thickness (above 7 atomic layers). These structural features corroborate earlier findings that nanoporosity is associated with severe Ni-leaching and hence must be considered as one of the major reasons for catalyst instability.

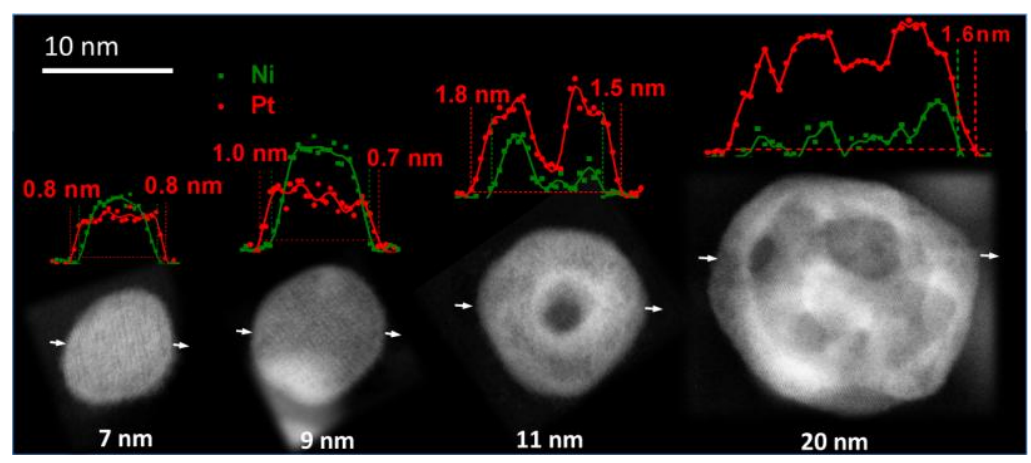

Figure 14 HAADF-STEM images and the corresponded EELS line profiles of NPs with different sizes in air-dealloyed $\mathrm{PtNi}_{3}$ catalyst after 10,000 cycles of stability test. Particles larger than ca. $10 \mathrm{~nm}$ steadily showed the formation of nanoporosity and, consequently, lower $\mathrm{Ni}$ content as well as larger Pt shell thickness. (Reprinted from ref. [38] (Top. Catal.), with permission of Springer. Remark: Graphs are based on data presented in [76].)

We can conclude that suppressing nanoporosity formation can be important to achieve a high stability of the Pt alloy catalyst. Based on this finding, it was hypothesized that the catalytic stability of the $\mathrm{PtNi}_{3}$ catalyst can be improved by controlling the initial particle size below ca. $10 \mathrm{~nm}$ to completely avoid nanoporosity $[38,76]$. This hypothesis was confirmed using a carbon-supported $\mathrm{PtNi}_{3} \mathrm{NP}$ catalyst with a much more uniform particle size distribution ranging between 3 and 10 nm (Figure 15a) [38]. The dealloyed catalyst exhibited both high mass activity and exceptionally high stability (Figure 15b). Its mass activity loss is only $11 \%$ after $10 \mathrm{~K}$ cycles and $24 \%$ after $30 \mathrm{~K}$ cycles. As such it met, for the first time, both the DOE 2017 targets [106] for cathode ORR catalyst activity and stability in RDE tests. All NPs remained non-porous even after $30 \mathrm{~K}$ cycles and showed a mild decrease in $\mathrm{Ni}$ content from $\mathrm{Pt}_{50} \mathrm{Ni}_{50}$ to $\mathrm{Pt}_{61} \mathrm{Ni}_{39}$.

These results and conclusions regarding dealloyed Pt-Ni NP ORR catalysts prompted the test of these catalysts in automotive-scale Membrane Electrode Assemblies tests under realistic PEMFC conditions. 


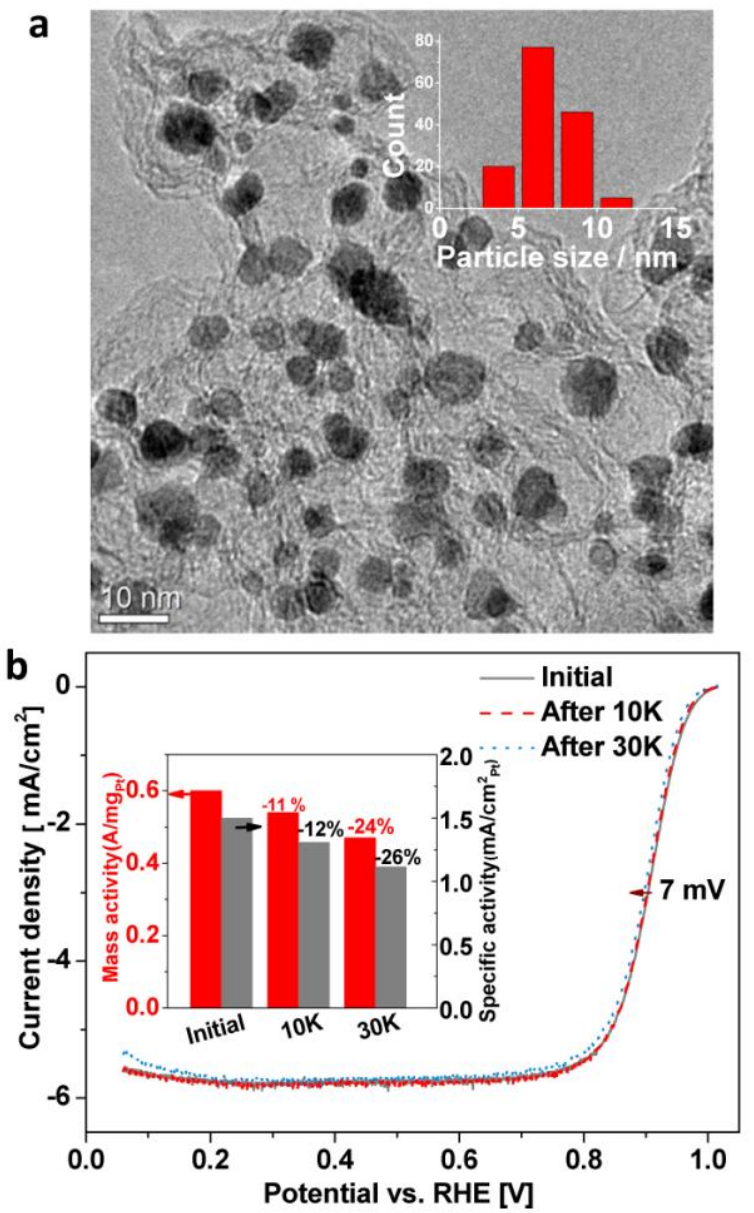

Figure 15 a) Typical TEM image of the $\mathrm{PtNi}_{3}$ catalyst with the particle size distribution mainly between 3-10 nm. b) ORR polarization curves of 3-10 nm D-PtNi ${ }_{3}$ catalyst before and after stability tests $(10,000$ and 30,000 potential cycles between 0.6 and $1.0 \mathrm{~V})$. The inset illustrates the mass activity and specific activity degradation after different cycles. (Reprinted from ref. [38] (Top. Catal.), with permission of Springer. Remark: Graphs are based on data presented in [76].)

\section{Dealloyed Pt-Ni core-shell ORR catalyst deployed in automotive PEM fuel cells}

To test the atomic-scale insights of section 5 regarding the size and composition effects of dealloyed $\mathrm{PtNi}_{3}$ catalyst in realistic fuel cell environments, sizecontrolled $\mathrm{PtNi}_{3} \mathrm{NP}$ precursor catalysts were dealloyed by inorganic liquid acid leaching [72], prior to deployment at the cathode of PEM fuel cells. The MEAs were subjected to a rigorous test of the cells' power performance and long term stability according to industry standards. As a reference, a $\mathrm{PtNi}_{3}$ precursor catalyst with a fairly broad $(5-20 \mathrm{~nm})$ particle size distribution was treated, deployed, and tested under identical conditions.

Figure 16a depicts the relation between Beginning of life (BOL) and End of life Pt-mass activity (30k cycled Mass activity) [72], both measured at $+0.9 \mathrm{~V}_{\text {cell }}$, of 
three MEAs with size-controlled Pt core-shell cathode ORR catalysts (blue solid circles). For comparison, the poorly size-controlled catalyst and a number of other data obtained from PEMFCs tested under comparable conditions are included. The red asterisk indicates the US DOE catalyst activity target for the year 2017 [106].

The dealloyed Pt catalyst with poor size control surpassed the initial activity target yet failed to comply with the end of life stability goal, in agreement with our atomic scale findings in the previous sections. In contrast, the size-controlled dealloyed Pt core-shell catalysts, dealloyed in sulphuric or nitric acid with or without thermal treatment, exhibited a previously unachieved BOL and EOL Pt mass activity, surpassing previously reported single fuel cell tests that employed Pt alloy catalyst at their cathode. In particular, the three dealloyed Pt-Ni catalysts met and even exceeded [72] the 2017 DOE catalyst development targets [106]. Dealloyed Pt-Ni NPs are currently considered the most promising cathode catalyst candidate for automotive fuel cell developers in future cell designs.

Figure $16 \mathrm{~b}$ traces the evolution and the current status of the Pt mass activity of state-of-art ORR Pt alloy electrocatalysts for automotive fuel cell cathodes [107]. Green solid symbols indicate fuel cell MEA measurements under realistic conditions, while open white symbol denote RDE measurements in liquid electrolyte. Spherical dealloyed Pt core-shell catalysts were first introduced in 2007. Later, dealloyed PtNi catalysts were explored [108, 109] and their performance in RDE and MEA conditions were reported [76, 110]. Since about 2010, shape-controlled Pt-Ni nanoparticles were investigated [111-113]. Pt-rich octahedral $\mathrm{Pt}_{3} \mathrm{Ni}$ nanocatalysts exhibited $\mathrm{Pt}$ mass activities of up to $0.7 \mathrm{~A} / \mathrm{mgPt}$ [113]. More recent work in this direction has then led to ORR catalysts with extremely high initial activities exceeding standard Pt catalyst by a factor of more than 50x [114, 115]. The preparation of these highly active materials involved the preparation of Pt-poor Pt-Ni precursor nanoparticle with octahedral or polyhedral shapes that were dealloyed by acid leaching and/or electrochemical corrosion. Their test in realistic MEA conditions and an assessment of their morphological and compositional durability is unclear to date and is subject of current investigations. 
a)

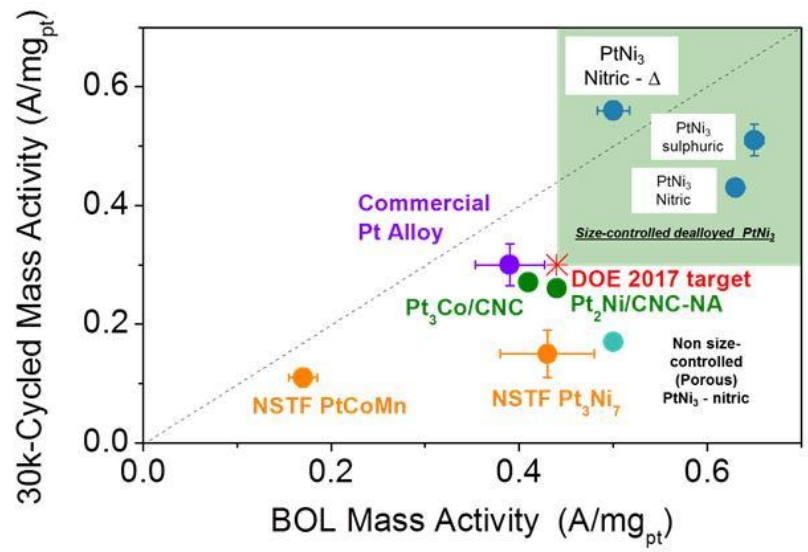

b)

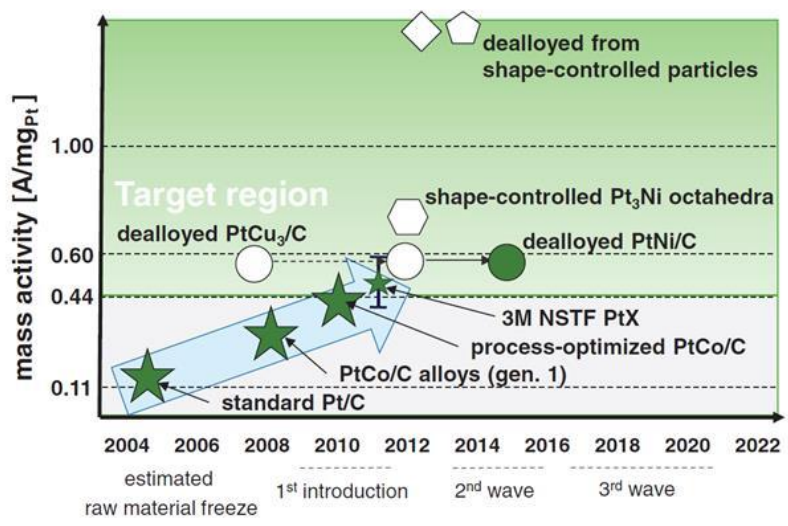

Figure 16 a) The end-of-life (EOL, 30k-cycled MEA) vs. beginning-of-life (BOL, conditioned MEA) Pt-mass activity of three MEAs containing size-controlled $\mathrm{PtNi}_{3}$ nanoparticle cathode catalysts which were dealloyed under three different conditions [72] (nitric acid leaching with subsequent thermal treatment: " $\mathrm{PtNi}_{3}$ nitric $-\Delta$ ", sulphuric acid leaching without thermal treatment: "PtNi ${ }_{3}$ sulphuric"; nitric acid leaching without thermal treatment: "PtNi ${ }_{3}$ nitric"), one MEA containing an acid-leached $\mathrm{PtNi}_{3}$ nanoparticle catalyst with broad size distribution [72], and MEA results from other reported work: $3 \mathrm{M}$ NSTF PtCoMn, NSTF $\mathrm{Pt}_{3} \mathrm{Ni}_{7}$ [116], $\mathrm{Pt}_{3} \mathrm{Co} / \mathrm{CNC}$ and $\mathrm{Pt}_{2} \mathrm{Ni} / \mathrm{CNC}$ [117], Supplier Pt Alloy and pure Pt $[48,118]$. The red asterisk and the red square region represent the DOE 2017 PEMFC cathode catalyst targets for BOL mass activity $(0.44 \mathrm{~A}$ $\left.\mathrm{mgPt}^{-1}\right)$ and EOL mass activity $\left(0.26 \mathrm{~A} \mathrm{mgPt}^{-1}\right)$, respectively [106]. (Reproduced with permission from ref. [72] - published by The Royal Society of Chemistry.)

b) Schematic of reported MEA mass activities (full figures) of Pt-based ORR catalysts appearing viable for mass manufacturing (green symbols) and interesting PGM-based concept catalyst showing promising RDE and in some cases MEA based mass activities (white symbols). Standard Pt/C, PtCo/C alloys (gen. 1) [118], process-optimized PtCo/C (gen. 2), dealloyed $\mathrm{PtCu}_{3}$ [119], 3M NSTF [120], dealloyed PtNi/C [72] and catalysts derived from dealloyed shapecontrolled Pt-alloy particles $[115,121]$. At the bottom of the figure are the estimated material design freeze periods for FCEVs which have been introduced today (2010 to 2012), for the fastfollower's FCEV introduction in 2017 to 2020 (2014 and 2016), and for the first wave during market expansion in 2020+ (around 2018+). (Reprinted from ref. [107] with permission of the Electrochemical Society.) 


\section{Conclusions}

This contribution reviewed aspects of the materials science and catalysis of dealloyed Pt alloy nanoparticle electrocatalysts for the electrocatalytic reduction of oxygen at PEMFC cathodes. Geometric lattice effects appear to play an important role in the enhanced catalytic ORR performance of the dealloyed nanoparticles compared to pure Pt nanoparticles. Solid core-shell structures appear to be superior to nanoporous particles in terms of residual non-noble metal content and durability. The core-shell structure is the predominant morphology, if the particle size of the PtX precursor particles is well controlled below a critical value. This calls for careful size control of the precursor alloy. Tests of size-controlled dealloyed Pt-Ni in single $50 \mathrm{~cm}^{2}$ PEM fuel cells under realistic automotive conditions confirmed that size controlled dealloyed Pt-Ni cathode ORR catalyst are able to meet and exceed the current activity and durability commercialization targets for 2017.

\section{Acknowledgements}

This work was supported by the German National Science Foundation (DFG) via grant STR 596/5-1 ("Nanoscale Pt Alloy electrocatalysts with well-defined shapes"). Partial support was received by the German Federal Ministry of Education and Research (Bundesministerium für Bildung und Forschung, BMBF) under the grant \#03SF0527A "LoPlaKats". S.K. acknowledges partial financial support by the Fuel Cell and Hydrogen Joint Undertaking (FCH JU) in Europe under the EU Horizon2020 framework (grant "INSPIRE").

\section{References}

[1] R. Cesareo, A. Bustamante, J. Fabian, S. Zambrano, W. Alva, L. Chero, M. del Carmen Espinoza, R. Rodriguez R, M. Seclen, F. Gutierrez V., E.B. Lévano, J. Gonzales A., M.A. Rizzutto, E. Poli, C. Calza, M. dos Anjos, R.T. Lopes, G.E. Gigante, G.M. Ingo, C. Riccucci, C. Elera, I. Shimada, V. Curay, M.G. Castillo, F. Lopes, Journal of Materials Science and Engineering B 1 (2011) 48-81.

[2] H. Lechtman, Sci. Am. 250 (1984) 56-63.

[3] M. Raney, Method of Preparing Catalytic Material, US Patent 1563 587, 1925.

[4] M. Raney, Method of producing Finely Divided Nickel, US Patent 1628 190, 1927.

[5] R. Heidersbach, Corrosion 24 (1968) 38-44.

[6] T.L. Barr, Abstr Pap Am Chem S 181 (1981) 192-ANYL.

[7] H.W. Pickering, Y.S. Kim, Corros Sci 22 (1982) 621-635.

[8] A.J. Davenport, K. Sieradzki, J Electrochem Soc 135 (1988) C348-C348.

[9] R.C. Newman, A. Mehta, T. Shahrabi, K. Sieradzki, J Electrochem Soc 135 (1988) C348C348.

[10] T.P. Moffat, F.R.F. Fan, A.J. Bard, J Electrochem Soc 138 (1991) 3224-3235.

[11] S.G. Corcoran, D. Wiesler, J. Barker, K. Sierradzki, Mater Res Soc Symp P 376 (1995) 377 -

382.

[12] J. Erlebacher, M.J. Aziz, A. Karma, N. Dimitrov, K. Sieradzki, Nature 410 (2001) 450-453.

[13] K. Sieradzki, N. Dimitrov, D. Movrin, C. McCall, N. Vasiljevic, J. Erlebacher, J Electrochem Soc 149 (2002) B370-B377.

[14] J. Erlebacher, K. Sieradzki, Scripta Mater 49 (2003) 991-996.

[15] J. Erlebacher, J Electrochem Soc 151 (2004) C614-C626.

[16] S. Parida, D. Kramer, C.A. Volkert, H. Rosner, J. Erlebacher, J. Weissmuller, Phys Rev Lett 97 (2006)

[17] N.A. Senior, R.C. Newman, Nanotechnology 17 (2006) 2311-2316. 
[18] N. Nakajima, H. Miyoshi, K. Nishizaki, T. Kitai, H. Uchida, M. Watanabe, Denki Kagaku 65 (1997) 876-877.

[19] M.T. Paffett, S. Gottesfeld, J Electrochem Soc 135 (1988) C348-C348.

[20] T. Fujita, P.F. Guan, K. McKenna, X.Y. Lang, A. Hirata, L. Zhang, T. Tokunaga, S. Arai, Y. Yamamoto, N. Tanaka, Y. Ishikawa, N. Asao, Y. Yamamoto, J. Erlebacher, M.W. Chen, Nat Mater 11 (2012) 775-780.

[21] R. Zeis, T. Lei, K. Sieradzki, J. Snyder, J. Erlebacher, J Catal 253 (2008) 132-138.

[22] G.J. Hutchings, Chemsuschem 3 (2010) 429-430.

[23] Y. Ding, Y.J. Kim, J. Erlebacher, Adv Mater 16 (2004) 1897-+

[24] Y. Ding, J. Erlebacher, J Am Chem Soc 125 (2003) 7772-7773.

[25] Y. Ding, M.W. Chen, J. Erlebacher, J Am Chem Soc 126 (2004) 6876-6877.

[26] Z. Liu, S. Koh, C. Yu, P. Strasser, J. Electrochem. Soc. 154 (2007) B1192-B1199.

[27] R. Srivastava, P. Mani, N. Hahn, P. Strasser, Angewandte Chemie International Edition 46 (2007) 8988-8991.

[28] S. Koh, P. Strasser, J Am Chem Soc 129 (2007) 12624-12625.

[29] P. Strasser, S. Koh, J. Greeley, Phys Chem Chem Phys 10 (2008) 3670-3683.

[30] J. Erlebacher, Solid State Phys 61 (2009) 77-141.

[31] P. Mani, R. Srivastava, P. Strasser, Journal of Physical Chemistry C 112 (2008) 2770-2778.

[32] P. Strasser, S. Koh, T. Anniyev, J. Greeley, K. More, C.F. Yu, Z.C. Liu, S. Kaya, D. Nordlund, H. Ogasawara, M.F. Toney, A. Nilsson, Nat Chem 2 (2010) 454-460.

[33] P. Mani, R. Srivastava, P. Strasser, Journal of Power Sources 196 (2011) 666-673.

[34] L. Gan, M. Heggen, S. Rudi, P. Strasser, Nano Letters 12 (2012) 5423-5430.

[35] M. Heggen, M. Oezaslan, L. Houben, P. Strasser, The Journal of Physical Chemistry C 116 (2012) 19073-19083.

[36] P. Strasser, in: W. Vielstich, H.A. Gasteiger, H. Yokokawa (Eds.), Handbook of Fuel Cells:Advances in Electrocatalysis, Materials, Diagnostics and Durability, John Wiley \& Sons Ltd, Chichester, West Sussex, UK, 2009, pp. 30-47.

[37] P. Strasser, Rev. Chem. Eng. 25 (2009) 255-295.

[38] L. Gan, C.H. Cui, S. Rudi, P. Strasser, Top Catal 57 (2014) 236-244.

[39] J. Snyder, T. Fujita, M.W. Chen, J. Erlebacher, Nat Mater 9 (2010) 904-907.

[40] J. Snyder, P. Asanithi, A.B. Dalton, J. Erlebacher, Adv Mater 20 (2008) 4883.

[41] I. Dutta, M.K. Carpenter, M.P. Balogh, J.M. Ziegelbauer, T.E. Moylan, M.H. Atwan, N.P. Irish, Journal of Physical Chemistry C 114 (2010) 16309-16320.

[42] C.X. Xu, R.Y. Wang, M.W. Chen, Y. Zhang, Y. Ding, Phys Chem Chem Phys 12 (2010) 239-246.

[43] J. Erlebacher, Phys Rev Lett 106 (2011) 225504.

[44] J. Snyder, Ian McCue, Ken Livi, J. Erlebacher, J Am Chem Soc 134 (2012) 8633-8645.

[45] H.A. Gasteiger, S.S. Kocha, B. Sompalli, F.T. Wagner, Appl Catal B-Environ 56 (2005) 9 -

[46] H.A. Gasteiger, N.M. Markovic, Science 324 (2009) 48-49.

[47] F.T. Wagner, B. Lakshmanan, M.F. Mathias, J Phys Chem Lett 1 (2010) 2204-2219.

[48] M.K. Debe, Nature 486 (2012) 43-51.

[49] J. Rossmeisl, P. Ferrin, G.A. Tritsaris, A.U. Nilekar, S. Koh, S.E. Bae, S.R. Brankovic, P. Strasser, M. Mavrikakis, Energy Environ. Sci. 5 (2012) 8335-8342.

[50] P. Strasser, J. Comb. Chem. 10 (2008) 216-224.

[51] X. Tuaev, J.P. Paraknowitsch, R. Illgen, A. Thomas, P. Strasser, Phys. Chem. Chem. Phys. 14 (2012) 6437-6440.

[52] N.R. Sahraie, U.I. Kramm, J. Steinberg, Y. Zhang, A. Thomas, T. Reier, J.-P. Paraknowitsch, P. Strasser, Nature Communications 6:8618 (2015).

[53] M. Busch, N.B. Halck, U. Kramm, S. Siahrostami, P. Krtil, J. Rossmeisl, Nano Energy 24, same special issue (2016).

[54] V. Stamenkovic, B.S. Mun, K.J.J. Mayrhofer, P.N. Ross, N.M. Markovic, J. Rossmeisl, J. Greeley, J.K. Norskov, Angew Chem Int Edit 45 (2006) 2897-2901.

[55] J. Greeley, I.E.L. Stephens, A.S. Bondarenko, T.P. Johansson, H.A. Hansen, T.F. Jaramillo, J. Rossmeisl, I. Chorkendorff, J.K. Norskov, Nat Chem 1 (2009) 552-556.

[56] J.L. Zhang, M.B. Vukmirovic, Y. Xu, M. Mavrikakis, R.R. Adzic, Angew. Chem. Int. Ed. 44 (2005) 2132-2135

[57] T. Toda, H. Igarashi, H. Uchida, M. Watanabe, J Electrochem Soc 146 (1999) 3750-3756.

[58] M.-k. Min, J. Cho, K. Cho, H. Kim, Electrochimica Acta 45 (2000) 4211-4217.

[59] U.A. Paulus, A. Wokaun, G.G. Scherer, T.J. Schmidt, V. Stamenkovic, V. Radmilovic, N.M. Markovic, P.N. Ross, Journal of Physical Chemistry B 106 (2002) 4181-4191.

[60] J.R.C. Salgado, E. Antolini, E.R. Gonzalez, Journal of Physical Chemistry B 108 (2004) $17767-17774$.

[61] H. Yang, N. Alonso-Vante, J.M. Leger, C. Lamy, Journal of Physical Chemistry B 108 (2004) 1938-1947. 
[62] H. Lv, D.L. Li, Y. Kang, D. Strmcnik, N.M. Markovic, V.R. Stamenkovic, Nano Energy 24, same special issue (2016).

[63] J. Zhang, Y. Mo, M.B. Vukmirovic, R. Klie, K. Sasaki, R.R. Adzic, Journal of Physical Chemistry B 108 (2004) 10955-10964.

[64] J. Zhang, F.H.B. Lima, M.H. Shao, K. Sasaki, J.X. Wang, J. Hanson, R.R. Adzic, Journal of Physical Chemistry B 109 (2005) 22701-22704.

[65] J.L. Zhang, M.B. Vukmirovic, K. Sasaki, A.U. Nilekar, M. Mavrikakis, R.R. Adzic, J Am Chem Soc 127 (2005) 12480-12481.

[66] R.R. Adzic, J. Zhang, K. Sasaki, M.B. Vukmirovic, M. Shao, J.X. Wang, A.U. Nilekar, M. Mavrikakis, J.A. Valerio, F. Uribe, Top Catal 46 (2007) 249-262.

[67] J. Zhang, K. Sasaki, E. Sutter, R.R. Adzic, Science 315 (2007) 220-222.

[68] J.X. Wang, H. Inada, L.J. Wu, Y.M. Zhu, Y.M. Choi, P. Liu, W.P. Zhou, R.R. Adzic, J Am Chem Soc 131 (2009) 17298-17302.

[69] V.R. Stamenkovic, B.S. Mun, K.J.J. Mayrhofer, P.N. Ross, N.M. Markovic, J Am Chem Soc 128 (2006) 8813-8819.

[70] V.R. Stamenkovic, B. Fowler, B.S. Mun, G.F. Wang, P.N. Ross, C.A. Lucas, N.M. Markovic, Science 315 (2007) 493-497.

[71] V.R. Stamenkovic, B.S. Mun, M. Arenz, K.J.J. Mayrhofer, C.A. Lucas, G.F. Wang, P.N. Ross, N.M. Markovic, Nat Mater 6 (2007) 241-247.

[72] B.H. Han, C.E. Carlton, A. Kongkanand, R.S. Kukreja, B.R. Theobald, L. Gan, R. O'Malley, P. Strasser, F.T. Wagner, Y. Shao-Horn, Energ Environ Sci 8 (2015) 258-266.

[73] L. Gan, P. Strasser, in: M. Shao (Ed.), Electrocatalysis for fuel cells: a non and low Platinum approach, Springer, London, 2013, pp. 533-560.

[74] M. Oezaslan, F. Hasché, P. Strasser, J. Phys. Chem. Lett. 4 (2013) 3273-3291.

[75] E. Bardal, Corrosion and Protection in Series Engineering Materials and Processes, Springer,

2004.

[76] L. Gan, M. Heggen, R. O'Malley, B. Theobald, P. Strasser, Nano Letters 13 (2013) 1131-

1138.

[77] F. Abild-Pedersen, J. Greeley, F. Studt, J. Rossmeisl, T.R. Munter, P.G. Moses, E. Skulason, T. Bligaard, J.K. Norskov, Phys. Rev. Lett. 99 (2007) 016105.

[78] S.G. Wang, G. Jones, M.P. Andersson, H. Falsig, L.C. Grabow, F. Abild-Pedersen, F. Studt, J.K. Norskov, T. Bligaard, Abstr Pap Am Chem S 242 (2011).

[79] B. Hammer, J.K. Nørskov, Advances in Catalysis 45 (2000) 71-129.

[80] J.R. Kitchin, J.K. Nørskov, M.A. Barteau, J.G. Chen, Phys Rev Lett 93 (2004) 156801.

[81] C. Yu, S. Koh, J.E. Leisch, M.F. Toney, P. Strasser, Faraday Discussions 140 (2009) 283-

296.

[82] L.A. Kibler, A.M. El - Aziz, R. Hoyer, D.M. Kolb, Angew. Chem. Int. Ed. 44 (2005) 2080-

2084.

[83] J.L. Zhang, M.B. Vukmirovic, K. Sasaki, A.U. Nilekar, M. Mavrikakis, R.R. Adzic, J. Am. Chem. Soc. 127 (2005) 12480-12481.

[84] M. Mavrikakis, B. Hammer, J.K. Norskov, Phys Rev Lett 81 (1998) 2819-2822.

[85] J.K. Nørskov, J. Rossmeisl, A. Logadottir, L. Lindqvist, J.R. Kitchin, T. Bligaard, H. Jonsson, J. Phys. Chem. B 108 (2004) 17886-17892.

[86] J. Rossmeisl, G.S. Karlberg, T. Jaramillo, J.K. Norskov, Faraday Discussions 140 (2009) $337-346$.

[87] R. Yang, J. Leisch, P. Strasser, M.F. Toney, Chemistry of Materials 22 (2010) 4712-4720.

[88] R. Yang, P. Strasser, M.F. Toney, The Journal of Physical Chemistry C 115 (2011) 9074-

9080 .

[89] S.R. Brankovic, J.X. Wang, R.R. Adžić, Surface Science 474 (2001) L173-L179.

[90] M. Oezaslan, M. Heggen, P. Strasser, J Am Chem Soc 134 (2012) 514-524.

[91] F. Hasché, M. Oezaslan, P. Strasser, ChemCatChem 3 (2011) 1805-1813.

[92] I.E.L. Stephens, A.S. Bondarenko, U.G. Andersen, J. Rossmeisl, I. Chorkendorff, Energ Environ Sci 5 (2012) 6744-6762.

[93] M. Oezaslan, F. Hasche, P. Strasser, Chemistry of Materials 23 (2011) 2159-2165.

[94] M. Oezaslan, F. Hasché, P. Strasser, Jounal of The Electrochemical Society 159 (2012) B394-B405.

[95] S. Koh, M.F. Toney, P. Strasser, Electrochimica Acta 52 (2007) 2765-2774.

[96] S. Koh, P. Strasser, J. Electrochem. Soc. 157 (2010) B585-B591.

[97] S. Rudi, X. Tuaev, P. Strasser, Electrocatalysis 3 (2012) 265-273.

[98] K. Ahrenstorf, O. Albrecht, H. Heller, A. Kornowski, D. Gorlitz, H. Weller, Small 3 (2007) 271-274.

[99] C. Wang, M.F. Chi, G.F. Wang, D. van der Vliet, D.G. Li, K. More, H.H. Wang, J.A. Schlueter, N.M. Markovic, V.R. Stamenkovic, Adv Funct Mater 21 (2011) 147-152.

[100] L. Gan, R. Yu, J. Luo, Z.Y. Cheng, J. Zhu, J Phys Chem Lett 3 (2012) 934-938. 
[101] X. Tuaev, S. Rudi, V. Petkov, A. Hoell, P. Strasser, ACS Nano DOI:10.1021/nn402406k (2013).

[102] D. Wang, Y. Yu, H.L. Xin, R. Hovden, P. Ercius, J.A. Mundy, H. Chen, J.H. Richard, D.A. Muller, F.J. DiSalvo, H.D. Abruña, Nano Letters 12 (2012) 5230-5238.

[103] S. Chen, W.C. Sheng, N. Yabuuchi, P.J. Ferreira, L.F. Allard, Y. Shao-Horn, Journal of Physical Chemistry C 113 (2009) 1109-1125.

[104] Z. Yu, J. Zhang, Z. Liu, J.M. Ziegelbauer, H. Xin, I. Dutta, D.A. Muller, F.T. Wagner, The Journal of Physical Chemistry C 116 (2012) 19877-19885.

[105] L. Gan, S. Rudi, C. Cui, M. Heggen, P. Strasser, accepteed in Small, DOI: 10.1002/smll.201600027 (2016).

[106] E.E.a.R.E. The US Department of Energy (DOE), Multi-Year Research, Development and Demonstration Plan, 2012

http://www1.eere.energy.gov/hydrogenandfuelcells/mypp/pdfs/fuel_cells.pdf.

[107] O. Gröger, H.A. Gasteiger, J.-P. Suchsland, J Electrochem Soc 162 (2015) A2605-A2622.

[108] L. Gan, M. Heggen, S. Rudi, P. Strasser, Nano Lett 12 (2012) 5423-5430.

[109] F. Hasche, M. Oezaslan, P. Strasser, J Electrochem Soc 159 (2012) B25-B34.

[110] A. Kongkanand, F. Wagner, Hydrogen and Fuel Cells and Vehicle Technologies Programs, Annual Merit Review DOE, Washington, DC, 2013, p http://www.hydrogen.energy.gov/pdfs/review13/fc087_kongkanand_2013_o.pdf

[111] J. Wu, L. Qi, H. You, A. Gross, J. Li, H. Yang, J. Am. Chem. Soc. 134 (2012) 11880-11883.

[112] J. Zhang, H. Yang, J. Fang, S. Zou, Nano Lett. 10 (2010) 638-644.

[113] J.B. Wu, A. Gross, H. Yang, Nano Lett. 11 (2011) 798-802.

[114] X. Huang, Z. Zhao, L. Cao, Y. Chen, E. Zhu, Z. Lin, M. Li, A. Yan, A. Zettl, Y.M. Wang, Science 348 (2015) 1230-1234.

[115] C. Chen, Y. Kang, Z. Huo, Z. Zhu, W. Huang, H.L. Xin, J.D. Snyder, D. Li, J.A. Herron, M. Mavrikakis, M. Chi, K.L. More, Y. Li, N.M. Markovic, G.A. Somorjai, P. Yang, V.R. Stamenkovic Science 343 (2014) 1339-1343.

[116] A. Steinbach, High Performance, Durable, Low Cost Membrane Electrode Assemblies for Transportation Applications, Annual Merit Review DOE Hydrogen and Fuel Cells and Vehicle Technologies Programs, Washington DC, http://www.hydrogen.energy.gov/pdfs/review14/fc104_steinbach_2014_o.pdf.

[117] B.N. Popov, Development of Ultra-low Doped-Pt Cathode Catalysts for PEM Fuel Cells, Annual Merit Review DOE Hydrogen and Fuel Cells and Vehicle Technologies Programs, Washington DC, 2014, p. http://www.hydrogen.energy.gov/pdfs/review14/fc088_popov_2014_o.pdf.

[118] F.T. Wagner, Yan, S. G., Yu, P. T., John Wiley \& Sons, Ltd, Chichester, 2009, p. 250.

[119] S. Koh, N. Hahn, C. Yu, P. Strasser, J Electrochem Soc 155 (2008) B1281-B1288.

[120] M.K. Debe, ECS Transactions 45 (2012) 47-68.

[121] C. Cui, L. Gan, M. Heggen, S. Rudi, P. Strasser, Nat Mater 12 (2013) 765-771. 

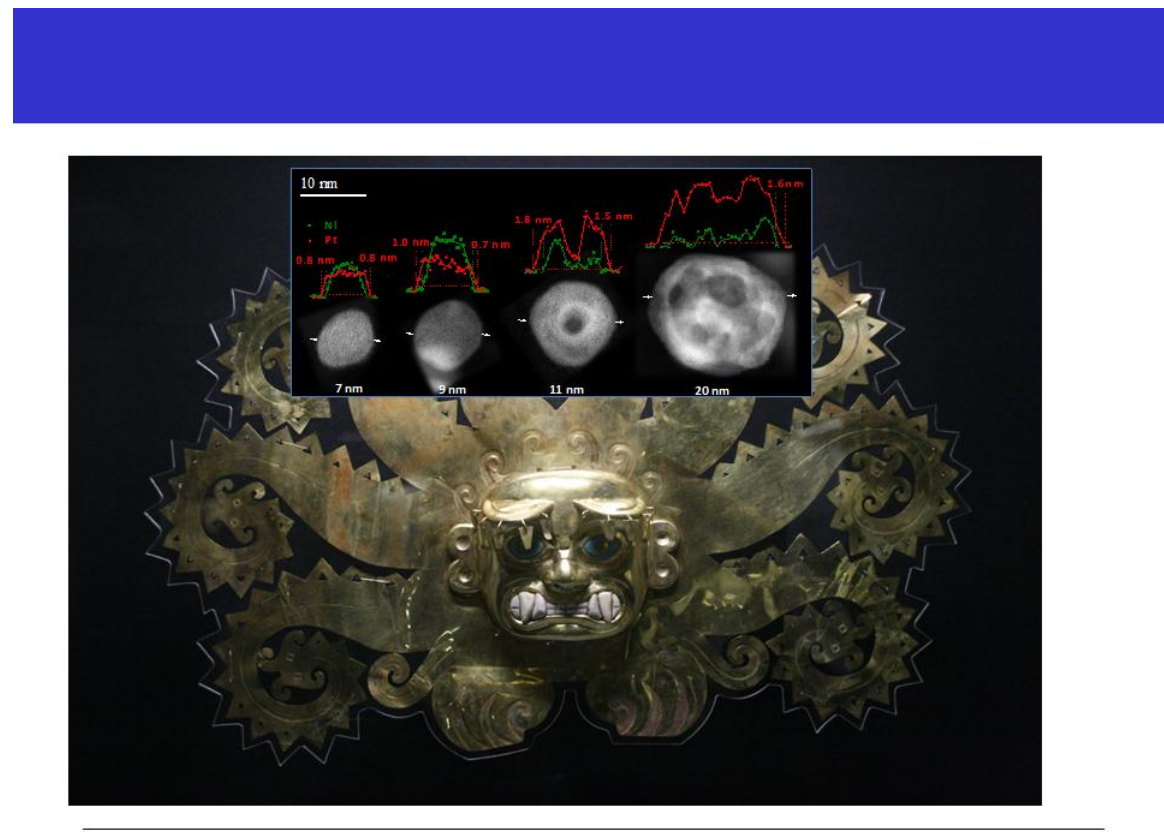